\title{
Polysialic acid and Siglec-E orchestrate negative feedback regulation of microglia activation
}

\author{
Hauke Thiesler $^{1,2} \cdot$ Julia Beimdiek ${ }^{1} \cdot$ Herbert Hildebrandt $^{1,2}$ (D)
}

Received: 4 December 2019 / Revised: 23 June 2020 / Accepted: 17 July 2020 / Published online: 28 July 2020

(c) The Author(s) 2020

\begin{abstract}
Polysialic acid (polySia) emerges as a novel regulator of microglia activity. We recently identified polysialylated proteins in the Golgi compartment of murine microglia that are released in response to inflammatory stimulation. Since exogenously added polySia is able to attenuate the inflammatory response, we proposed that the release of polysialylated proteins constitutes a mechanism for negative feedback regulation of microglia activation. Here, we demonstrate that translocation of polySia from the Golgi to the cell surface can be induced by calcium depletion of the Golgi compartment and that polysialylated proteins are continuously released for at least $24 \mathrm{~h}$ after the onset of inflammatory stimulation. The latter was unexpected, because polySia signals detected by immunocytochemistry are rapidly depleted. However, it indicates that the amount of released polySia is much higher than anticipated based on immunostaining. This may be crucial for microglial responses during traumatic brain injury (TBI), as we detected polySia signals in activated microglia around a stab wound in the adult mouse brain. In BV2 microglia, the putative polySia receptor Siglec-E is internalized during lipopolysaccharide (LPS)induced activation and in response to polySia exposure, indicating interaction. Correspondingly, CRISPR/Cas9-mediated Siglec-E knockout prevents inhibition of pro inflammatory activation by exogenously added polySia and leads to a strong increase of the LPS response. A comparable increase of LPS-induced activation has been observed in microglia with abolished polySia synthesis. Together, these results indicate that the release of the microglia-intrinsic polySia pool, as implicated in TBI, inhibits the inflammatory response by acting as a trans-activating ligand of Siglec-E.
\end{abstract}

Keywords Immune balance $\cdot$ Inflammatory activation $\cdot$ Innate immune response $\cdot$ Traumatic brain injury $\cdot$ Sialic acidbinding immunoglobulin-like lectins

\section{Introduction}

The glycan polysialic acid (polySia) is the $\alpha 2,8$-linked homopolymer of $\mathrm{N}$-acetylneuraminic acid (Neu5Ac), the most common sialic acid in vertebrates [1]. PolySia is mainly known as a posttranslational modification of the neural cell adhesion molecule (NCAM). PolySia on NCAM is presented

Electronic supplementary material The online version of this article (https://doi.org/10.1007/s00018-020-03601-z) contains supplementary material, which is available to authorized users.

Herbert Hildebrandt

hildebrandt.herbert@mh-hannover.de

1 Institute of Clinical Biochemistry, Hannover Medical School, Carl-Neuberg-Straße 1, 30625 Hanover, Germany

2 Center for Systems Neuroscience Hannover (ZSN), Bünteweg 2, 30559 Hanover, Germany at the cell surface and plays a major role during brain development by modulating NCAM binding and attenuating other cell surface interactions [2, 3]. Recently, however, we identified a pool of polySia in primary and stem cell-derived murine microglia and human THP-1 macrophages occurring on two other, unrelated protein carriers, namely neuropilin 2 (NRP2) and the E-selectin ligand 1 (ESL-1, a.k.a. GLG1) $[4,5]$. Surprisingly, this polySia pool is not found at the cell surface, but restricted to the Golgi compartment and in contrast to polySia on NCAM, which can be synthesized by the two Golgi-resident polysialyltransferases ST8SIA2 and ST8SIA4 [6], it is exclusively produced by ST8SIA4 [4]. In acute brain slice cultures, Golgi-localized polySia appears during injury-induced activation of microglia, and inflammatory activation by stimulation with bacterial lipopolysaccharide (LPS) causes a rapid loss of cell-associated polySia, because polySia-NRP2 and polySia-ESL-1 are no longer 
retained in the Golgi, but translocated to the cell surface and released by ectodomain shedding [5].

Application of soluble, free or protein-bound polySia attenuates proinflammatory activation of primary and stem cell-derived murine microglia, murine BV2 microglia, and human THP-1 macrophages [4, 5, 7-9]. Based on this effect of exogenously applied polySia, we proposed that the release of the cell-intrinsic pool of polysialylated proteins provides negative feedback regulation of microglia and macrophage activation. This is supported by the observation that LPSinduced activation is potentiated in ST8SIA4-deficient primary murine microglia [4], because the deprivation of polySia synthesis and thereby the absence of polySia shedding may lead to a loss of feedback inhibition. However, the receptor responsible for polySia sensing in this assumed feedback loop remained elusive.

Sialylated glycans are recognized by members of the I-type lectin family called sialic acid-binding immunoglobulin-like lectins (Siglecs) that are primarily found on hematopoietic and immune cells [10-12]. Conventionally, Siglecs are divided into those that are structurally conserved across mammals, and the group of CD33 (Siglec-3)-related Siglecs that vary considerably between species. Siglecs are type I transmembrane proteins with an amino-terminal sialic acidbinding V-set domain. In their cytoplasmic domain, most of the CD33-related Siglecs have immunoreceptor tyrosinebased inhibitory motifs (ITIMs), which typically counteract activating signaling from other immune receptors [11, 13]. In the human system, the CD33-related macrophage- and microglia-specific Siglec-11 has been shown to bind polySia and to attenuate proinflammatory activation $[8,9,14]$. Siglec-11 has no murine orthologue [15], but glycan array binding revealed that murine Siglec-E, among a wide range of other sialoglycans, binds $\alpha 2,8$-linked di- and trisialic acid [16] and recent in vitro data indicated that polySia encapsulated E. coli $\mathrm{K} 1$ bind to Siglec-E as efficiently as to human Siglec-11 [17]. Moreover, lentiviral knockdown of Siglec-E abolished the responsiveness of LPS-induced microglia to a fraction of polySia with an average degree of polymerization of 20 sialic acid residues (avDP20) [9], but the authors emphasize that compared to Siglec-11-positive human THP-1 macrophages, about tenfold more avDP20 was needed to elicit the same inhibitory response in mouse microglia with uncompromised expression of Siglec-E. This conspicuous discrepancy raises doubts, if Siglec-E qualifies as a receptor of microglial polySia release.

In the current study, we address open questions concerning the mechanism of the LPS-induced discharge of polysialylated proteins from the Golgi of microglia and the time course of their release. In addition, we demonstrate a transient accumulation of polySia in injury-induced microglia in vivo and provide evidence that Siglec-E is involved in negative feedback inhibition by acting as a receptor for polySia on proteins shed by LPS-induced microglia.

\section{Materials and methods}

\section{Cells, reagents and antibodies}

BV2 microglia were kindly provided by Gerd Bicker, University of Veterinary Medicine, Hannover, Germany. If not indicated otherwise, BV2 cells were cultured in DMEM with $4.5-\mathrm{g} / \mathrm{l}$ glucose containing $100-\mu \mathrm{g} / \mathrm{ml}$ penicillin/streptomycin and supplemented with $2.5 \%$ fetal bovine serum (all from Gibco, Rockville, MD, USA). Passaging was performed at about $80 \%$ confluency and cells were detached mechanically with a cell scraper. All experiments performed in this study were obtained between passages 6 and 20. The plasmid pX330A-1 $\times 2$ for CRISPR/spCas9-D10A-mediated knockout [18] was a kind gift from Takashi Yamamoto (Addgene, Watertown, MA, USA, plasmid \#58766; https ://n2t.net/addgene:58766; RRID:Addgene_58766). The plasmid DHC\#4731 containing a P2A element followed by eGFP [19] was kindly provided by Dirk Heckl, Hannover Medical School, Hannover, Germany. Endosialidase was produced as described before [20]. Trisialic acid, i.e., $\alpha 2,8$ linked sialic acid with a degree of polymerization (DP) of 3 , and tetrasialic acid (DP4) were from Nacalai Tesque (Kyoto, Japan); $\alpha 2,8$-linked polySia (colominic acid from E. coli) was from Sigma-Aldrich [St Louis, MO, USA, catalog no. (cat. \#) C5762, lot no. 110M1383]. Streptavidin and biotin were from Vector Laboratories (Burlingame, CA, USA), Cy3-conjugated streptavidin from Rockland (Limerick, PA, USA). Lipopolysaccharide (LPS) extracted from E. coli serotype O127:B8, 4-chloro- $m$-cresol (4-C $m \mathrm{C})$, TAK-242, 1,1'-diheptyl-4,4'-bipyridinium dibromide (DHBP), genistein, and biotinyl tyramide were from Merck, Darmstadt, Germany.

The following monoclonal (mAb) or polyclonal $(\mathrm{pAb})$ antibodies were used: Siglec-E-specific sheep pAb (kindly provided by Paul Crocker, University of Dundee, Scotland, $3.2 \mu \mathrm{g} / \mathrm{ml}$ ), ESL-1-specific rabbit pAb (kindly provided by Martin Wild, Münster, Germany, 1:3000), polySia-specific mouse mAb 735 ([21]; produced in-house as described by Werneburg et al. [4] and used at $2 \mu \mathrm{g} / \mathrm{ml}$ for immunofluorescence or $1 \mu \mathrm{g} / \mathrm{ml}$ for immunoblotting), CD11b-specific rat mAb (AbD Serotec, Raleigh, NC, USA, cat. \#MCA74GA, 1:250), Iba1-specific rabbit pAb (Wako Chemicals, Neuss, Germany, cat. \#019-19741, 1:300), giantin-specific rabbit pAb (Covance, Denver, PA, USA, cat. \#PRB-114C, 1:10,000), NRP2-specific rabbit mAb D39A5 (Cell Signaling, Beverly, MA, USA, cat. \#3366S, 1:1000), EEA1 (early endosomal antigen 1)-specific antibody rabbit pAb 
(Santa Cruz Biotechnology, Santa Cruz, CA, cat. \#sc-33585, $1: 100)$.

Secondary antibodies were HRP-conjugated donkey anti-sheep IgG (Sigma-Aldrich, cat. \#A-3415, 1:1000), Cy3-conjugated donkey anti-rat IgG (Merck, cat. \#AP189C, 1:500), Alexa Fluor 647-conjugated donkey anti-rabbit IgG (Thermo Fisher Scientific, Waltham, MA, USA, cat. \#A-31573, 1:500), Alexa Fluor 488-conjugated donkey antimouse IgG (Thermo Fisher Scientific, cat. \#A21020, 1:500), Alexa Fluor 488-cojugated goat anti-mouse IgG (Thermo Fisher Scientific, cat. \#A11029, 1:500), HRP-conjugated goat anti-rabbit IgG (Sigma-Aldrich cat. \#6157, 1:15,000), and HRP-conjugated goat anti-mouse $\operatorname{IgG}$ (Southern Biotech, Birmingham, AL, USA, cat. \#1010-05, 1:20,000).

\section{Immunocytochemistry}

For immunocytochemistry, cells were seeded on glass coverslips in 24-well plates at a density of 20,000 cells per well. After a given treatment, as specified for each experiment separately, cells were washed once in PBS, fixed with $4 \%$ paraformaldehyde in PBS for $20 \mathrm{~min}$ at room temperature (RT) and stored in PBS at $4{ }^{\circ} \mathrm{C}$. Immunofluorescence staining (IF) and embedding was performed as described by Werneburg et al. [4] with minor modifications by permeabilizing with $0.4 \%$ Triton X-100 in PBS for 15 min, blocking for $2 \mathrm{~h}$ at $37^{\circ} \mathrm{C}$, and washing three times with $0.1 \%$ Triton in PBS and once with water, before mounting.

For Siglec-E immunostaining in combination with other primary antibodies, biotin-tyramide signal amplification was used. Briefly, after permeabilization, peroxidase activity was blocked by incubation with $0.3 \% \mathrm{H}_{2} \mathrm{O}_{2}$ in PBS for 15 min at RT. After washing, endogenous biotin was blocked by adding streptavidin and, after further washing, biotin (1:10 in PBS, 15 min at RT, each). After another washing step, cells were incubated with primary antibodies as described above, and for 45 min with HRP-conjugated anti-sheep IgG for the detection of Siglec-E-specific antibody, followed by washing with TBS pH 7.6 and incubation in TBS with 0.1 -M imidazole, $0.001 \% \mathrm{H}_{2} \mathrm{O}_{2}$, and $2.5-\mu \mathrm{g} / \mathrm{ml}$ biotinyl tyramide for $10 \mathrm{~min}$ at RT. After three washes with PBS, enzymatically produced biotin precipitate was detected by Cy3-conjugated streptavidin (1:1.000 in PBS with $0.1 \%$ Triton X-100 and $2 \%$ BSA, 45-min RT), before fluorescently labeled secondary antibodies were added and cells were embedded, as described above.

Specificity of double- and triple-immunostaining procedures was controlled by omitting one of the primary or secondary antibodies at a time. For polySia immunoreactivity, specificity was additionally controlled by the loss of immunoreactivity after degradation of polySia with 6- $\mu \mathrm{g} /$ $\mathrm{ml}$ endosialidase applied during blocking. This enzyme degrades polySia with high specificity [20].

\section{Immunoaffinity chromatography}

Stationary phase consisting of polySia-specific mAb 735 coupled to protein A sepharose beads (GE Healthcare, Amersham, UK) was prepared using standard protocols [22]. A C16/20 column (GE Healthcare) was packed with 3.2-ml beads coupled with 2.1-mg antibody per ml beads (bed volume) and chromatography was performed at RT on an Äkta Pure 25 protein purification system (GE Healthcare) at a flow rate of $0.4 \mathrm{ml} / \mathrm{min}$ with $20-\mathrm{mM}$ Tris-HCl, $\mathrm{pH} 8.0$, $10-\mathrm{mM} \mathrm{MgCl}_{2}$ containing $90-\mathrm{mM} \mathrm{NaCl}$ for loading and 2-M $\mathrm{NaCl}$ for elution. Conductivity and absorption at 214 and $280 \mathrm{~nm}$ were recorded.

Supernatant of LPS-induced BV cells cultured in serumfree medium was passed through a $0.22-\mu \mathrm{m}$ syringe filter prior to loading and following loading to the column elution was started after a stable baseline was obtained. For subsequent analysis by immunoblotting (see below), fractions of $0.4 \mathrm{ml}$ were collected and $1.6-\mathrm{ml}$ propanone per fraction was added to precipitate proteins overnight at $-20^{\circ} \mathrm{C}$. After centrifugation at $16,000 \times g$ for $15 \mathrm{~min}$, pellets were air dried and reconstituted in $20-\mu \mathrm{l}$ Laemmli buffer.

\section{Immunoprecipitation and immunoblotting}

Immunoprecipitation (IP) of polySia from cell lysates using M-280 tosyl-activated Dynabeads (Thermo Fisher Scientific) covalently coupled to mAb 735, SDS-PAGE and analyses of IP fractions by immunoblotting and enhanced chemiluminescence detection were performed as described by Werneburg et al. [5]. Fractions obtained by immunoaffinity chromatography were blotted on nitrocellulose membrane (GE Healthcare) and analyzed with the Odyssey Infrared Imaging System (LI-COR Biosciences, Bad Homburg, Germany) as described previously [23]. For enzymatic removal of polySia prior to SDS-PAGE, samples in Laemmli buffer were treated with $6-\mu \mathrm{g} / \mathrm{ml}$ endosialidase for $45 \mathrm{~min}$ at $37^{\circ} \mathrm{C}$.

\section{Anion exchange chromatography}

Polysialic acid was separated on the Äkta Pure 25 system equipped with a $22 \times 50$ guard column followed by a DNAPac PA-100 column $22 \times 250$ (Thermo Fisher Scientific). Chromatography was performed at RT with a flow rate of $3.5 \mathrm{ml} / \mathrm{min}$ using $10-\mathrm{mM}$ Tris- $\mathrm{HCl} \mathrm{pH} 8.0$ during loading. Elution was performed in $10-\mathrm{mM}$ Tris- $\mathrm{HCl} \mathrm{pH} 8.0$ with consecutive steps of linear $\mathrm{NaCl}$ gradients and steady concentrations as follows: 4-ml 0-70 mM, 44-ml 70-180 mM, 0.5$\mathrm{ml} 180 \mathrm{mM}, 16-\mathrm{ml} 180-220 \mathrm{mM}, 48-\mathrm{ml} 220-280 \%$, 40-ml 280-320 mM, 80-ml 320-355 mM, and 40-ml 355-385 mM, 40-ml 385-410 mM, 44-ml 410-432 mM, 40-ml

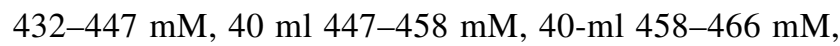
$40-\mathrm{ml} 466-470 \mathrm{mM}, 40-\mathrm{ml} 470-472 \mathrm{mM}$ and $45-\mathrm{ml} 1 \mathrm{M}$ 
$\mathrm{NaCl}$. Conductivity and absorption at 214 and $280 \mathrm{~nm}$ were recorded.

\section{Brain sections}

To conserve animals, sections of mouse brains with cortical lesions were drawn from a control group of animals used in a prior study, which was designed to examine drug effects on epileptogenesis induced by intrahippocampal kainate injection [24]. Sections were kindly provided by Wolfgang Löscher, University of Veterinary Medicine, Hanover, Germany. The animal experiments were performed according to the EU council directive 2010/63/EU and the German Law on Animal Protection. Ethical approval was granted by the Lower Saxony State Office for Consumer Protection and Food Safety (LAVES, project number 14/1659). As described in detail elsewhere [24], 8- to 10-week-old male NMRI mice were anesthetized with chloral hydrate $(500 \mathrm{mg} / \mathrm{kg}$ i.p) and received a unilateral stereotactic injection of kainate ( $1 \mathrm{nM}$ in 50-nl saline) through the cortex into the CA1 sector of the dorsal hippocampus. Injections were carried out with a $0.5-\mu 1$ microsyringe over $60 \mathrm{~s}$ and after injection, the syringe was kept in place for another $2 \mathrm{~min}$ to limit reflux along the wound channel. In addition, mice received daily i.p. injections of saline. Seven days after the brain injection, and before the onset of clinical seizures [25], mice were perfused and paraffin-embedded brains were sectioned at $3 \mu \mathrm{m}$ for use in immunohistochemistry.

\section{Immunohistochemistry}

Paraffin sections were rehydrated and antigen retrieval was performed in 400-mM Tris- $\mathrm{HCl}$ pH 9.0 with 1-mM EDTA and $0.05 \%$ Tween- 20 at $90{ }^{\circ} \mathrm{C}$ for $10 \mathrm{~min}$. After permeabilization with $0.4 \%$ Triton X-100 in PBS for 30 min and blocking with $2 \%$ BSA, $0.1 \%$ Triton in PBS for $3 \mathrm{~h}$ at $37^{\circ} \mathrm{C}$, primary antibodies were incubated in blocking buffer at $4{ }^{\circ} \mathrm{C}$ overnight. All other steps and specificity controls were carried out as described for immunocytochemistry, except for the endosialidase treatment, which was performed with $10 \mu \mathrm{g} / \mathrm{ml}$.

\section{Microscopy, image acquisition, cell counting and densitometry}

Microscopy was performed with Axio Observer.Z1 equipped with an ApoTome module for structured illumination, AxioCam MRm digital camera, and Zen 2012 (blue edition) software (Carl Zeiss Microscopy). A $20 \times$ Plan-Apochromat objective with a numerical aperture of 0.8 was used to acquire optical sections of $1.62-\mu \mathrm{m}$ (488 channels), $1.75-\mu \mathrm{m}$ (568 channels) or $2.09-\mu \mathrm{m}$ thickness (647 channels), and five optical sections were merged to a maximal intensity projection, respectively. For 3D reconstruction, stacks of 40 optical sections were obtained using a $63 \times$ Plan-Apochromat oil immersion objective with a numerical aperture of 1.4. Identical settings were used for all samples within one experimental setting. Images were arranged using PowerPoint (Microsoft Office 2010). For the evaluation of immunostained cells in cultures, cell counts were performed on randomly chosen frames as specified in the respective figure legends. For the evaluation of Siglec-E immunoreactivity, cells were encircled manually and signal intensities were determined using the polygon contour measurement tool of the ZEN software. For the evaluation of Iba-1- and polySiapositive cells on brain sections, immuno-positive cells were counted in bins of $0-50,50-200$ and $200-400 \mu \mathrm{m}$ away from the wound channel.

\section{Generation of Siglec-E knockout cells}

The CRISPR/spCas9-D10A strategy $[18,26]$ was used to generate Siglec-E knockout cells. The all-in-one CRSIPR/ spCas9-D10A vector pX330A-1 $\times 2$ (Addgene plasmid \# 58766) was modified by insertion of a P2A element followed by eGFP in C-terminal orientation. The latter was obtained from plasmid DHC\#4731 as a template by overlap extension PCR with the primers 5'- GGAAGAGAATGCTGGCCTCT $-3^{\prime}$ and $5^{\prime}$ - AATCCAGAATTCGATTATCGATTTAACGC $-3^{\prime}$ containing recognition sequences for BsmI and EcoRI. In addition, the following guide RNAs (gRNA) targeting the sialic acid-binding V-domain of Siglec-E located within the first exon were inserted: 5'- CACCGCAGACGCAAAGAT TCCATCG -3' (leading strand gRNA1), 5'- AAACCGATG GAATCTTTGCGTCTGC -3' (reverse strand gRNA1), 5'CACCGTGTACCAGAATCCATGAACT -3' (leading strand gRNA2), 5'- AAACAGTTCATGGATTCTGGTACAC -3' (reverse strand gRNA2).

To transfect BV2 cells, electroporation with the Neon Nucleofector (Thermo Fisher Scientific) was used according to the manufacturer's instructions. $1 \times 10^{5}$ cells were treated with a 30-ms pulse of $1325 \mathrm{~V}$ followed by incubation for $12 \mathrm{~h}$ in conditioned medium consisting of supernatant from $1 \times 10^{5}$ BV2 cells per ml, cultured for $24 \mathrm{~h}$ in the absence of penicillin and streptomycin, which was filtered through a $0.22-\mu \mathrm{m}$ syringe filter and supplemented with FCS to a final concentration of $7.5 \%$. Subsequently, cells were cultured in conditioned medium with penicillin and streptomycin supplemented with 5\% FCS for 3 days and 2.5\% FCS for 7 days, followed by standard cultivation conditions. GFP-positive cells were identified, clones were isolated by limited dilution and Siglec-E mutations were assessed by sequencing of genomic PCR products obtained with primers flanking the targeted site (forward: 5'- CAGTTTTAGCTGGACATGCTG -3', reverse: 5'- CGGGTTTCCTTCACTGCTT -3'). 


\section{Nitrite Assay}

Nitric oxide (NO) production by LPS treatment was evaluated by the colorimetric Griess assay, detecting the stable NO breakdown product nitrite in cell culture supernatants. The assay was performed as described before [7], with the following modifications: $5 \times 10^{4}$ cells were seeded in 96-well plates. After adherence for $4 \mathrm{~h}$, the medium was changed and cells were cultured for $2 \mathrm{~h}$ in the presence of $60-\mu \mathrm{M}$ minocycline, where indicated. After another medium change, cells were kept for $24 \mathrm{~h}$ in $200-\mu \mathrm{l}$ medium for further treatment (see results), before $150 \mu \mathrm{l}$ of cell culture supernatant were collected and centrifuged at $3000 \times g$ for $5 \mathrm{~min}$. Nitrite concentrations were assessed by reacting $70 \mu \mathrm{l}$ of the supernatant for $20 \mathrm{~min}$ with $70-\mu \mathrm{l}$ Griess reagent consisting of $1 \%$ (4-[(4-aminobenzene)sulfonyl]aniline), $0.05 \% \mathrm{~N}$-1-napthylethylenediamine dihydrochloride and $2.5 \% \mathrm{HCl}$.

\section{RNA isolation and quantitative real-time RT-PCR}

Total RNA was isolated using TRIzol (Thermo Fisher Scientific), and cDNA was generated as described [4] using RevertAid H Minus reverse transcriptase (Thermo Fisher Scientific). Quantitative real-time PCR of mouse SiglecE, TNF and IL-6 was performed in 10- $\mu$ 1:2 diluted BIO SyGreen Lo-ROX mix (PCR Biosystems, London, UK) with ImageQuantQ3 and ImageQuant software (Thermo Fisher Scientific) using the comparative threshold cycle $\left(\Delta C_{\mathrm{T}}\right)$ method as described elsewhere [27] with HPRT and PPIA as reference genes [28]. The following primers were used: HPRT, 5'- TTCCTCATGGACTGATTATGG ACA-3' (forward) and 5'- AGAGGGCCACAATGTGAT GG -3' (reverse); PPIA, 5'- CCACAGTCGGAAATGGTG AT-3' (forward) and 5'- TGCACTGCCAAGACTGAATG-3' (reverse); TNF, 5'- CTGTAGCCCACGTCGTAGC-3' (forward) and 5'- TTGAGATCCATGCCGTTG-3' (reverse) [29]; IL-6, 5'-GGCCTTCCCTACTTCACAAG -3' (forward) and $5^{\prime}$-ATTTCCACGATTTCCCAGAG -3' (reverse) [30]; Siglec-E 5'-TGGTACAGGGAAGGAACCGA -3' (forward) and 5'-GTGAGGGCTGTTACAACCAGA -3' (reverse). The NCBI primer designing tool with Primer3 version 4.1 [31, 32] was used to select Siglec-E-specific primers.

\section{Statistics}

Statistical analysis was performed using GraphPad Prism 7 software (GraphPad, San Diego, CA, USA). Unpaired Student's $t$-test, one-way analysis of variance (ANOVA) followed by Tukey's post hoc test, and mixed two-way ANOVA followed by Holm-Sidak post hoc test were applied as indicated. Normality and equality of variances were assessed by the Shapiro-Wilk and the Brown-Forsythe test, respectively.

\section{Results}

\section{BV2 cells produce polySia on NRP2 and ESL-1}

The murine microglial cell line BV2 is a commonly used model system and suited to study inflammatory microglia activation [33]. As shown before [7], LPS-induced activation of these cells can be dose dependently inhibited by externally applied polySia. For the use of BV2 cells in the current study, we validated, if these cells also recapitulate the previously described features of primary and stem cellderived microglia concerning the production of polySia $[4,5]$. Immunofluorescence (IF) revealed that BV2 cells accumulate polySia in the Golgi compartment (Fig. 1a) and immunoprecipitation with polySia-specific antibody followed by Western blot analysis demonstrated the presence of the two polySia carrier proteins NRP2 and ESL-1 (Fig. 1b). When treated with the polySia degrading enzyme endosialidase, both proteins exhibited the small shift towards lower apparent molecular mass that is characteristic for the loss of polySia [5] (Fig. 1b). Moreover, BV2 cells show a depletion of the Golgi-resident polySia pool after proinflammatory stimulation with LPS for $24 \mathrm{~h}$ (Fig. 1c, d). Consistent with the previous results [7], the application of $500 \mathrm{ng} /$ $\mathrm{ml}$ of polySia (colominic acid) caused a significant inhibition of LPS-induced NO production (Fig. 1e). As shown by HPLC analysis, the specific polySia batch used in the current study comprised chain lengths ranging from a degree of polymerization (DP) of 5 to DP $>100$ with an average DP of about 50 (for a DP profile, see Online Resource 1). The effective molar concentration, therefore, was approximately $30 \mathrm{nM}$. In contrast to the effect of polySia, the same molar concentration of trisialic acid (DP3) was not able to dampen the inflammatory response (Fig. 1e). Although statistically not significant, the slight increase of NO production observed in BV2 cells treated with polySia alone might be caused by endotoxin contamination of the polySia preparation. Replication by an independent experiment, however, yielded no evidence for such an effect [nitrite levels relative to LPS-treated cells were $0.042 \pm 0.011$ for untreated and $0.046 \pm 0.008$ for polySia (> DP4) treated BV2 cells, respectively (means \pm s.d., $n=4$ independent cultures each, comparison by unpaired, two-sided $t$ test, $p=0.56$ )]. Collectively, these results establish that BV2 cells qualify for studies on the mechanisms of polySia release and perception.

\section{Golgi retention and release of polySia are calcium sensitive}

A key feature of proinflammatory activation is the elevation of the cytosolic $\mathrm{Ca}^{2+}$ level by the depletion of the intracellular $\mathrm{Ca}^{2+}$ stores of the endoplasmic reticulum (ER) and 
Fig. 1 Validation of polySia expression and polysialylated proteins in BV2 microglia. a Immunofluorescence staining of polySia colocalized with the Golgi marker giantin. Cell shape is highlighted by co-staining with the microglia/macrophage marker CD11b. Nuclei were counterstained with DAPI (blue). Scale bar, $20 \mu \mathrm{m}$. b Immunoprecipitation (IP) of polysialylated proteins from lysate of $10^{7} \mathrm{BV} 2$ cells using polySia-specific mAb 735-conjugated magnetic beads followed by Western blot (WB) detection with polySia-specific antibody (left), or by joint incubation with NRP2- and ESL-1-specific antibodies (right). Where indicated, IP fractions were treated with endosialidase $($ endo + ), to remove polysialic acid. Protein bands were assigned according to the apparent molecular weights of NRP2 and ESL-1 as previously detected in primary and stem cell-derived murine microglia or in mouse brain tissue [5; see text for details]. c Compared to untreated controls (ctrl), incubation of BV2 cultures with $1-\mu \mathrm{g} / \mathrm{ml}$ LPS for $24 \mathrm{~h}$ leads to the loss of polySia signals in almost all cells. Nuclei were counterstained with DAPI (blue). Scale bar, $50 \mu \mathrm{m}$. d Loss of polySia-positive cells after LPS treatment, as indicated. Individual values and means of 5 evaluated frames per culture condition, with a minimum of 20 cells each are plotted and significant difference by two-tailed t-test is indicated (*** $p<0.001$ ). e PolySia with DP $>4$ but not trisialic acid (DP3) attenuates the LPS-induced production of NO. Nitrite levels in the supernatant of BV2 cells cultured for $24 \mathrm{~h}$ in the presence or absence of 30-nM trisialic acid (DP3), 500-ng/ml poly-Sia (approximately $30 \mathrm{nM}$, see text for details), and/or $1-\mu \mathrm{g}$ / $\mathrm{ml}$ LPS, as indicated. Individual values and means from 3 independent treatments per group are plotted. One-way ANOVA indicated significant differences $(p<0.0001)$ and results from Tukey's post hoc test are shown for comparisons between the LPS-treated groups $(* p<0.05)$

Golgi compartment [34]. This can be mimicked by the pharmacological activation of ryanodine receptors (RyRs) [35]. Application of the RyR agonist 4-CmC for 10 min caused a translocation of polySia from the Golgi to the cell surface, which was comparable to the effect of LPS (Fig. 2b, c; for a quantitative assessment see Fig. 2e). After 20 min, however, the cell-associated polySia signals in LPS-treated cells had vanished completely; whereas, the 4-CmC-treated cells retained cell surface staining (Fig. 2b, c, e). Conversely, the RyR receptor antagonist DHBP prevented the LPS-induced translocation of the Golgi-resident polySia pool (Fig. 2d, e). This implies that the translocation of polysialylated proteins from the Golgi compartment to the cell surface in response to proinflammatory activation of microglia is triggered by lowering the calcium level within the Golgi compartment.

\section{Continuous release of polySia by LPS-induced BV2 cells}

When analyzed by IF, polySia immunoreactivity of LPSinduced microglia completely vanished within $2 \mathrm{~h}$ and polysialylated proteins could be retrieved by IP from large amounts of cell culture supernatant followed by Western blot detection [5]. To monitor the release into the extracellular space, we established the sensitive detection of polysialylated proteins in cell culture supernatants of LPStreated BV2 cells by immunoaffinity chromatography with
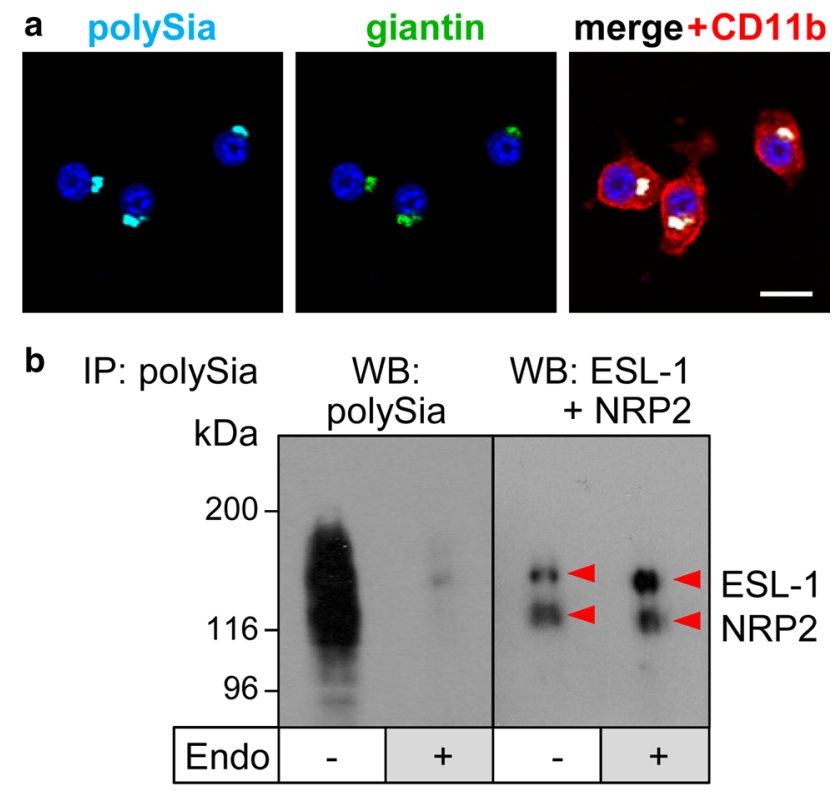

C

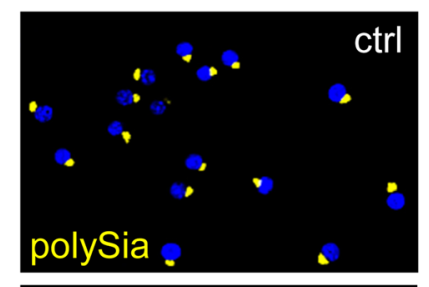

d
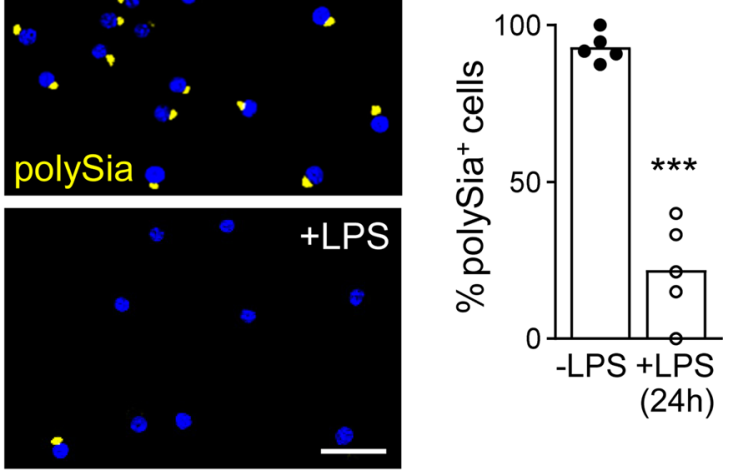

e

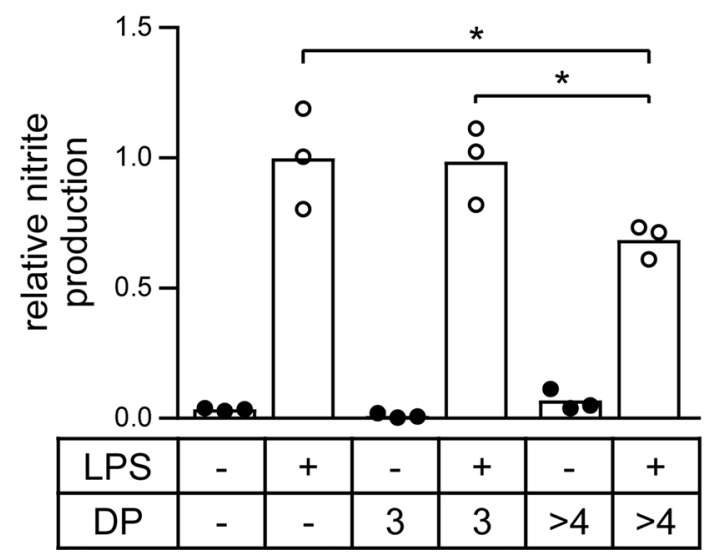

polySia-specific antibody. Western blot analysis confirmed the presence of polysialylated protein in the pooled fractions corresponding to the absorption peak at $\lambda=214 \mathrm{~nm}$ obtained after the onset of the elution by a salt gradient (fractions 22-24; Fig. 3a, b). In contrast to the highly sensitive detection of polySia by immunoblotting, yields were too low to 
also verify the presence of ESL-1 or NRP2 in these fractions. Importantly, no polySia was detected in later fractions (26-28) or in the fractions showing similar absorption peaks during washing of the column (fractions 18-20), corroborating the specific detection of polysialylated protein. With this system, a moderate peak could be detected in supernatants of BV 2 cells collected during the first $4 \mathrm{~h}$ after LPS induction (Fig. 3c, middle). Unexpectedly, for supernatants collected between 4 and $24 \mathrm{~h}$ after the onset of LPS treatment a much larger peak was obtained (Fig. 3c, right). As a rough estimate for the amount of protein-bound polySia released by LPS-induced BV2 microglia, the peaks at $214 \mathrm{~nm}$, indicative for polySia, were compared to respective peaks obtained by application of defined amounts of the polySia fraction used at $500 \mathrm{ng} / \mathrm{ml}$ to inhibit the LPS-induced NO production (see Fig. 1e). As a result, approximately $400 \mathrm{ng}$ of polySia could be detected in 1-ml cell culture supernatant obtained from $10^{6}$ LPS-induced BV2 cells after $4 \mathrm{~h}$, indicating that the release of protein-bound polySia and the amount of experimentally added polySia were in a similar range. Importantly, as estimated from the peak areas, roughly 5-times more polySia-bearing protein accumulated in the cell culture supernatant during the $20 \mathrm{~h}$ of the second incubation as compared to the first 4-h period.

The latter indicates that, despite the rapid depletion of polySia signals detected by immunocytochemistry, polysialylated proteins are continuously released over at least $24 \mathrm{~h}$ after inflammatory activation of microglia. The amount of released polySia, therefore, can be much higher than anticipated based on immunostaining. Importantly, this also means that it will not be possible to directly detect by immunohistochemistry, if polySia is released from activated microglia into the brain parenchyma.

\section{Detection of polySia-positive microglia in TBI}

The presence of polySia in activated microglia after TBI was addressed in adult mice seven days after an injection of kainate through the cortex into the CA1 sector of the dorsal hippocampus. Serial sections of paraffin-embedded brain from five lesioned animals were investigated by staining for polySia and Iba-1. As shown before, the hippocampal kainate injection causes microglia activation in the hippocampus and adjacent cortical areas but, apart from the wound channel, not in the outer cortical layers [24]. Therefore, microglia around the wound channel was evaluated only in superficial areas of the cortex. All five specimen displayed the polySia and Iba-1 patterns of the representative section shown in Fig. 4. In areas distant from the wound channel (indicated by the dotted line in Fig. 4a, b), Iba-1 staining revealed microglia with ramified morphology indicative for the quiescent state [36, 37] (Fig. 4b and detail in c). Closer to the lesion, microglia had shorter and thicker processes
(Fig. 4d), characteristic for the transition into a reactive state in response to injury; whereas, rounded, amoeboid cells without defined processes at the site of the lesion indicate a fully activated state of phagocytic microglia (Fig. 4f). Notably, only a few polySia-positive dots were detected in some distance around the wound located in microglia with rounded morphology (Fig. 4a, b, e; for a quantitative assessment, see Fig. 4g, h). Enzymatic removal of polySia with endosialidase eliminated all of these dots in Iba-1-positive cell, but not some of the scattered smaller signals, which, therefore, are considered to be nonspecific (see Online Resource 2). Attempts to co-stain with the Siglec-E-specific antibody successfully used for immunocytochemistry (see below) or with the Golgi marker giantin failed, but the dotshaped cellular pattern corresponds to the appearance of Golgi-localized polySia during the lesion-induced activation of microglia in acute brain slice cultures [5]. The distribution in a halo around the wound channel indicates accumulation of polySia in the Golgi of injury-induced microglia, which is lost during further activation. Analogous to the continuous release of polySia after loss of Golgi-localized polySia by inflammatory activation of microglia in vitro, this pattern suggests polySia shedding by injury-activated microglia in the brain parenchyma during TBI in vivo.

\section{Diverging mRNA and protein patterns of Siglec-E upon LPS induction}

In accordance with the previous reports on bone marrowderived macrophages [38, 39], Siglec-E mRNA expression levels were strongly increased in LPS-treated BV2 microglia (Fig. 5a). The evaluation of Siglec-E protein patterns by IF, however, revealed abundant Siglec-E immunoreactivity on the surface of untreated cells (Fig. 5b, left), which was drastically reduced and restricted to a few immunoreactive patches after $24 \mathrm{~h}$ of LPS treatment (Fig. 5b, right). 3D reconstruction at higher magnification (Fig. 5b, lower panels) not only corroborated the strong reduction of Siglec-E at the cell surface and the loss of perinuclear polySia, but also revealed some small polySia-immunoreactive puncta within the LPS-treated cells, which may represent export vesicles engaged in continuous shedding of polysialylated protein.

Based on the discrepancy between Siglec-E mRNA and protein detection, and because Siglecs can be internalized upon ligand binding or antibody-mediated crosslinking [38, 40], we investigated if LPS induction leads to endocytosis of Siglec-E. After 10 min of LPS treatment, Siglec-E immunoreactive dots were detected within the cells and some, but few of them colocalized with EEA1, a well-characterized marker of early endosomes in clathrin-dependent and -independent pathways of endocytosis [41] (Fig. 5c). In some cases, polySia colocalized with the EEA1- and Siglec-E-positive vesicle-like structures but most of the abundant polySia-positive 

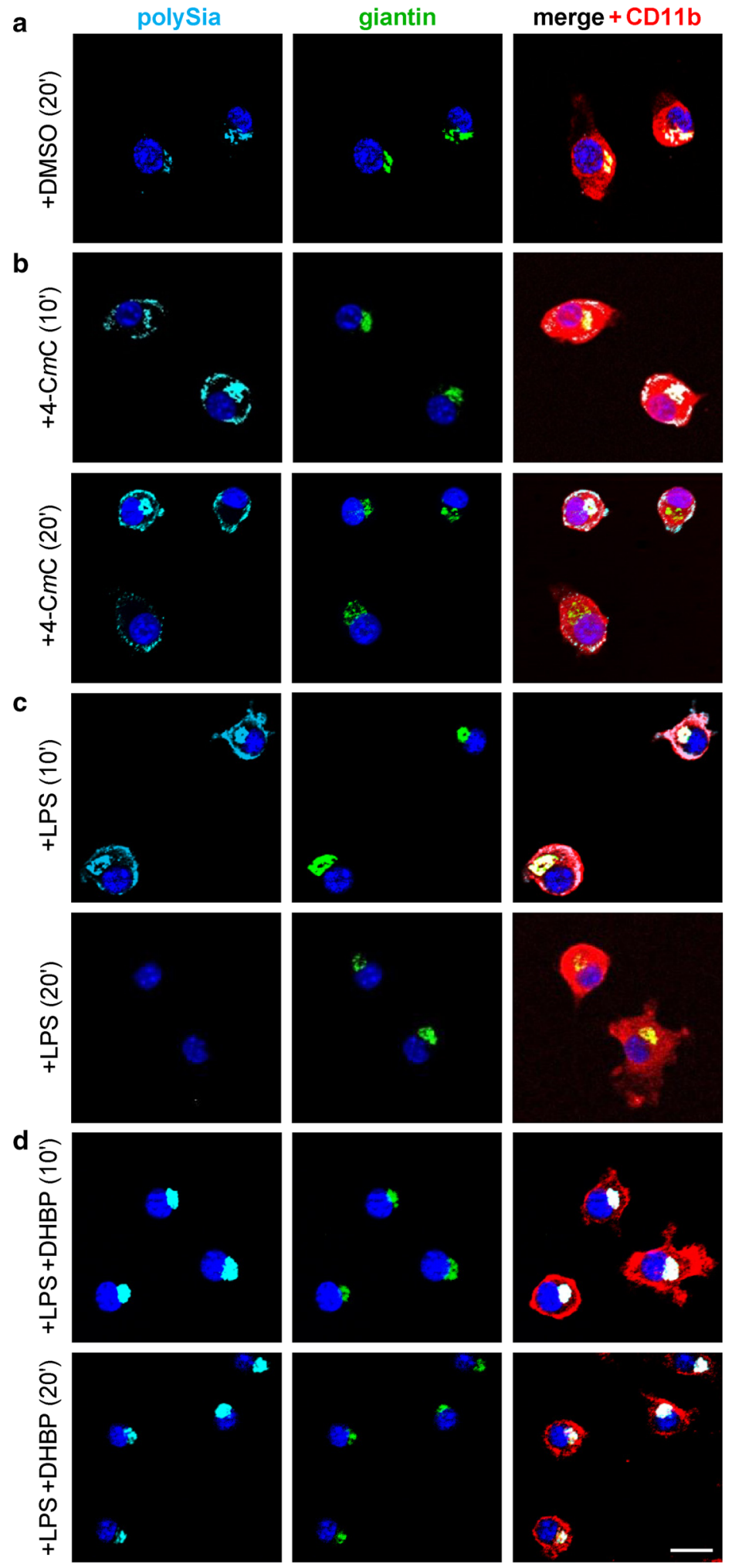
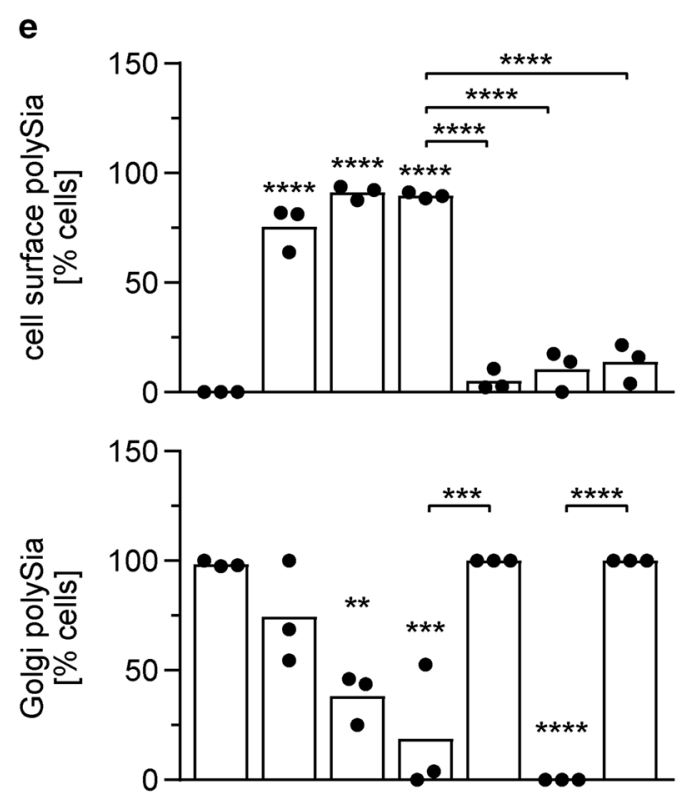

\begin{tabular}{|c|c|c|c|c|c|c|c|}
\hline DMSO & $20^{\circ}$ & $10^{\prime}$ & $20^{\prime}$ & $10^{\prime}$ & $10^{\prime}$ & $20^{\prime}$ & $20^{\prime}$ \\
\hline 4-CmC & - & $10^{\prime}$ & $20^{\prime}$ & - & - & - & - \\
\hline LPS & - & - & - & $10^{\prime}$ & $10^{\prime}$ & $20^{\prime}$ & $20^{\prime}$ \\
\hline DHBP & - & - & - & - & $10^{\prime}$ & - & $20^{\prime}$ \\
\hline
\end{tabular}

puncta are not colocalized with these markers, most likely because these structures denote secretory vesicles delivering the polysialylated proteins from the Golgi to the cell surface. In contrast to the strong reduction of Siglec-E after LPS treatment, incubation for 20 min with LPS in the presence of genistein, an inhibitor of clathrin-independent endocytosis [42], caused a massive accumulation of Siglec-E at the cell surface (Fig. 5d; for a quantitative assessment, see Fig. 5i). A comparable accumulation was achieved by genistein treatment of cells that were previously activated with LPS for $20 \mathrm{~h}$ 
4Fig. 2 PolySia staining patterns in BV2 cells treated for 10 or $20 \mathrm{~min}$ with $1-\mu \mathrm{l} / \mathrm{ml} \operatorname{DMSO}(\mathbf{a}), 50-\mu \mathrm{M}$ RyR agonist 4-CmC (b), 1- $-\mu \mathrm{g} / \mathrm{ml}$ LPS (c), or $1-\mu \mathrm{g} / \mathrm{ml}$ LPS together with $10-\mu \mathrm{M}$ RyR antagonist DHBP (d), and quantitative assessment (e), as indicated. Per well, a minimum of 10 cells in 3 randomly selected frames with at least 3 cells each were evaluated and percentages of cells with detectable polySia signals at the cell surface (upper graph) or co-localized with the Golgi marker giantin (lower graph) were calculated. Individual values and means of 3 wells per condition are plotted. For each data set, one-way ANOVA indicated significant differences $(p<0.0001)$ and results from Tukey's post hoc test are shown for comparisons against the DMSO control and for selected group comparisons $(* * p<0.01$, $* * * p<0.001, * * * * p<0.0001)$. 4-CmC and DHBP were added as $1-\mu \mathrm{l} / \mathrm{ml}$ stock solution in DMSO. Giantin and CD11b were co-stained to visualize the Golgi compartment and the cells' shape, respectively. Nuclei were counterstained with DAPI (blue). Scale bar, $20 \mu \mathrm{m}$. See text for a description of treatment effects

(Fig. 5e, f, i). Notably, genistein may also interfere with LPSinduced TLR4 activation [43], but selective inhibition of TLR4 signaling by application of TAK-242 [44] to the cell culture supernatant of LPS-induced cells for $10 \mathrm{~min}$ was not causing cell surface accumulation of Siglec-E (Fig. 5f, right; i). However, similar to genistein, TAK-242 treatment led to reappearance of intracellular, perinuclear polySia in some of the cells. Assuming that the internalization of Siglec-E is caused at least in part by its interactions with the protein-bound polySia released by LPS-induced BV2 microglia and that the reappearance of perinuclear polySia signals indicates a reduction of this release, the internalization of Siglec-E should come to a halt, if TAK-242 was applied after removal of the cell culture supernatant containing previously released polySia. Indeed, recurrence of Siglec-E signals at the surface of LPS-treated cells was observed, when TAK-242 was added by replacing the cell culture medium (Fig. 5g, i). To directly test if internalization of Siglec-E can be induced by interactions with polySia, protein-free polySia was applied to BV2 microglia. After 20 min of incubation, Siglec-E signals at the surface of otherwise untreated cells were clearly reduced (Fig. 5h, i). Short-term exposure for $1 \mathrm{~min}$ had no such effect, ruling out the possibility that engagement of Siglec-E with polySia blocks its recognition by the Siglec-E-specific antibody used in the current study.

Together, these data reveal that Siglec-E is continuously produced in LPS-induced BV2 microglia, which is consistent with the high Siglec-E mRNA levels of LPS-treated cells. The data also indicate that polySia release and SiglecE internalization are regulated by different, TLR4-dependent and TLR4-independent pathways, respectively, and provide first evidence that Siglec-E is internalized in response to polySia as a trans-interacting ligand.

\section{Knockout of Siglec-E potentiates LPS-induced activation and eliminates the response to polySia}

CRISPR/spCas9-mediated genome editing was used to generate a single Siglec-E-negative BV2 cell clone (clone D19, Fig. 6a, see Online Resource 3 for sequence analysis of induced mutations) and a mixed pool of four other SiglecE-negative clones (see Online Resource 4 for IF analysis of Siglec-E loss). These cells were used to corroborate if Siglec-E is accountable for the response of microglia to externally applied polySia and to address a role of Siglec-E in the proposed negative feedback inhibition of LPS-induced microglia activation by the shedding of polysialylated proteins. Consistent with our previous study, showing potentiated LPS induction of polySia-negative microglia [4], proinflammatory activation was initially monitored by the detection of NO-derived nitrogen species with the Griess assay.

Comparative analysis of wildtype $\left(\right.$ Siglece $\left.{ }^{+/+}\right)$and SiglecE-deficient BV2 cells (Siglece ${ }^{-/}$, clone D19) revealed that both responded to LPS with a strong increase in NO production (Fig. 6b). This response could be inhibited in both lines by preincubation with minocycline, a widely used inhibitor of proinflammatory microglia polarization [45]. In contrast, the attenuation of the LPS-induced increase by addition of exogenous polySia was abolished in the Siglec-E-deficient line and the response towards LPS was substantially stronger. To test for the possibility of an unspecific clonal effect as the basis for the altered responsiveness, the experiment was repeated with a mixture of another four Siglece ${ }^{-/-}$clones. As shown in Online Resource 5, the outcome was basically the same, i.e., a dramatically higher LPS-induced NO production than in wildtype cells that could still be inhibited by preincubation with minocycline, but no longer by the addition of polySia. Furthermore, the Siglec-E-negative clone D19 displayed a significantly more pronounced increase in the mRNA levels of the proinflammatory cytokines tumor necrosis factor (TNF) and interleukin-6 (IL-6) over $24 \mathrm{~h}$ of LPS treatment, although there was a slight delay in upregulation during the early phase of LPS induction (Fig. 6c, d). Taken together, these findings indicate that the release of microglia-intrinsic polySia attenuates the inflammatory response by acting as a trans-activating ligand of Siglec-E.

\section{Discussion}

The current study provides the first indication that injuryinduced activation leads to intracellular accumulation of poly-Sia in murine microglia in vivo. Comparable to the delayed and slowly increasing appearance of Golgi-localized polySia during microglia activation in acute brain slices over five days of culture [5], Iba-1-positive cells with 
a

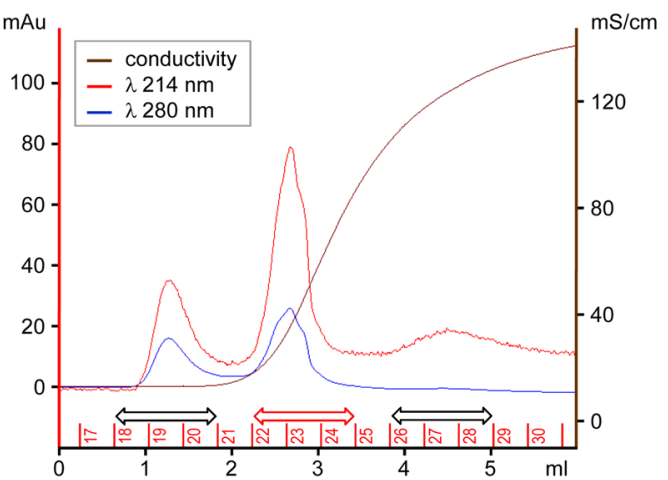

b

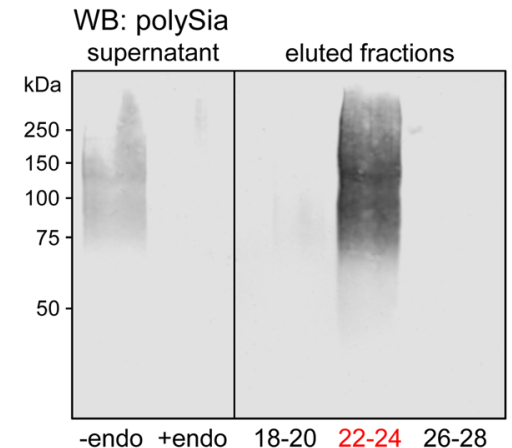

C

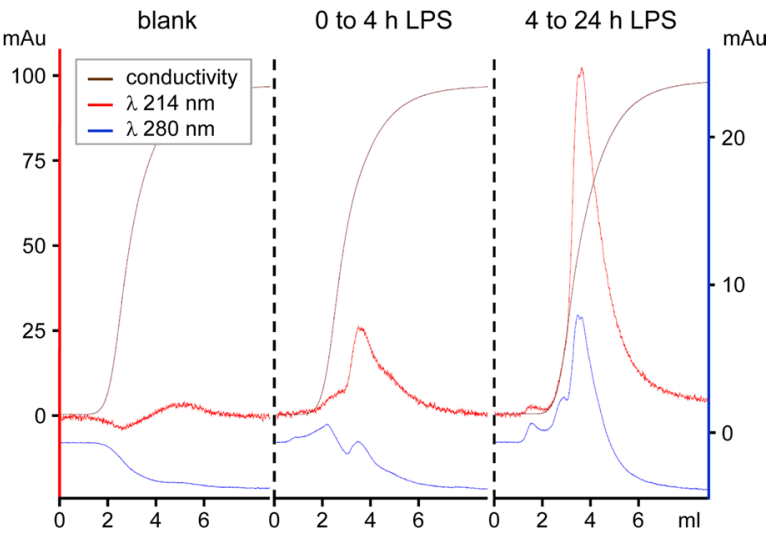

Fig. 3 Detection of polysialylated proteins released by LPS-induced BV2 microglia. a Elution profile of cell culture supernatants collected from $2.5 \times 10^{7} \mathrm{BV} 2$ cells treated with $10-\mu \mathrm{g} / \mathrm{ml}$ LPS for $24 \mathrm{~h}$ and applied to immunoaffinity chromatography with polySia-specific antibody. The increase of conductivity (brown line) denotes the onset of elution with 2-M NaCl. Detection at $214 \mathrm{~nm}$ and $280 \mathrm{~nm}$ (red and blue line), indicative for the presence of sialic acid and protein, respectively, resulted in peaks during washing (fractions 18-20) and during elution (fractions 22-24). b Western blot detection of polysialylated protein in the cell culture supernatant prior to immunopurification (left panel) and in the pooled fractions 22-24, but not in fractions $18-20$ and $26-28$ of the chromatogram shown in a (right panel). Specificity of polySia detection in the supernatant was controlled by enzymatic removal of polySia with endosialidase (+ endo). c Elution profile of cell culture supernatants as in a, but collected from $3 \times 10^{7}$ $\mathrm{BV} 2$ cells during the first $4 \mathrm{~h}$ or, after changing the medium, between 4 and $24 \mathrm{~h}$ after the onset of LPS treatment, respectively. The left panel shows an elution profile without sample (blank) strong perinuclear polySia signals featuring the morphology of activated microglia were detected seven days after brain lesion. These cells were rare and located at least 50- $\mu \mathrm{m}$ deep in the parenchyma around the wound channel, indicating that they are microglia rather than infiltrating macrophages. Although microglia activation peaks between three and five days after TBI [46], it has been shown in a rat TBI model that microglia acquire a predominantly proinflammatory activation phenotype at seven days post-injury [47]. We, therefore, assume that cultured microglia, which consistently display an accumulation of polySia in the Golgi compartment, correspond to a transient activation state of polySiapositive microglia in TBI. In analogy to the continuous shedding of polysialylated proteins by activated microglia in vitro, the absence of polySia signals in fully activated microglia situated directly adjacent to the lesion points towards a release of polySia. Furthermore, the absence of Golgi-confined polySia in ramified microglia located more distant from the lesion site confirms respective findings on quiescent microglia in murine brain slice cultures [5]. As a proof of principle, these data indicate that polySia can be produced by activated microglia in vivo. Future studies should follow up the time course of its appearance and ask for its potential impact on pathological microglia activation as well as on the outcome of TBI.

Our in vitro experiments with murine BV2 microglia corroborate data from primary and stem cell-derived microglia by demonstrating that polySia is presented on the two carrier proteins ESL-1 and NRP2, which, based on a glycoproteomic analysis of stem cell-derived microglia, constitute the pool of Golgi-confined polysialylated proteins in these cells [5], and that LPS-induced inflammatory activation causes a rapid translocation of polySia to the cell surface [5]. Consistent with the LPS-induced mobilization of internal calcium stores through activation of RyRs [34, 48], the release from the Golgi could be mimicked by treatment with the RyR agonist 4-C $m \mathrm{C}$; whereas, inhibition by the corresponding antagonist DHBP prevented the LPS-induced translocation. Notably, the trans-Golgi compartment, where polysialylation takes place, behaves as a calcium store that can be selectively mobilized by RyRs $[49,50]$. Thus, calcium depletion initiates the release of polySia-ESL-1 and polySia-NRP2 by abrogating their retention in the Golgi compartment.

As shown before, polySia-negative ESL-1 maintains its Golgi localization in LPS-induced microglia; while, polySia-negative NRP2 is distributed over the entire cell before and after activation $[4,5]$. Therefore, and in the absence of any other obvious similarity between NRP2 and ESL-1, polysialylation is likely to form the basis for the common regulation of Golgi retention and release. ST8SIA4, responsible for polysialylation of ESL-1 and NRP2 in microglia [4, 5], interacts with the nascent polySia chains and with the protein acceptors [51, 52]. 


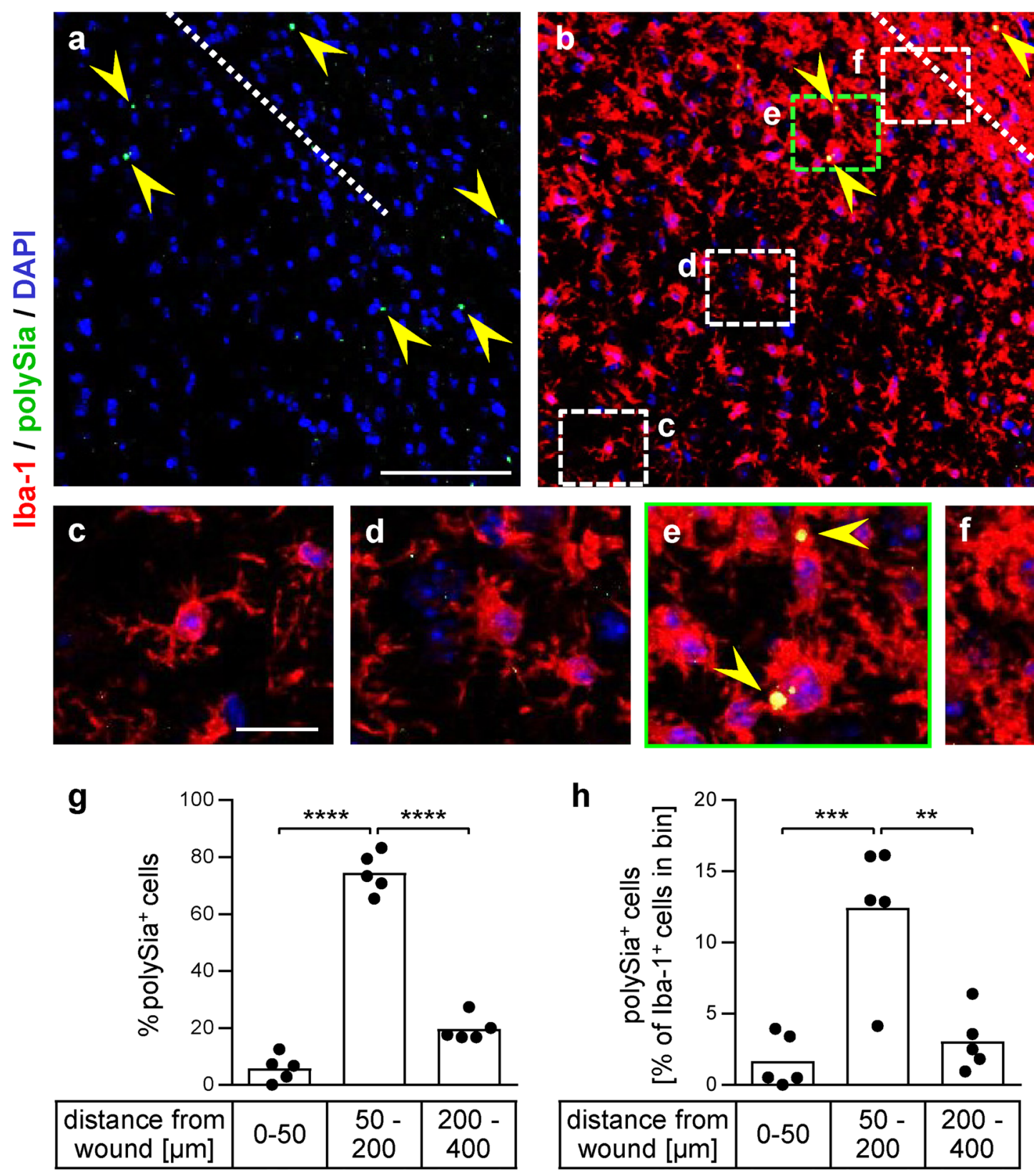

Fig. 4 PolySia-positive microglia in TBI. Immunofluorescence detection of polySia (green, marked by yellow arrowheads) and Iba-1 (red) one week after injury by an injection through the mouse cortex. a, b Overview of polySia signals around the wound channel (a), merged with Iba-1 staining (b). The wound channel is indicated by a dotted line. Nuclei were counterstained with DAPI (blue). c-f Higher magnification views of the boxed areas highlighted in $\mathbf{b}$. See text for a detailed description. Scale bars, $100 \mu \mathrm{m}$ in $\mathbf{a}$ and $\mathbf{b}, 20 \mu \mathrm{m}$ in $\mathbf{c}$. $\mathbf{g}$, h Quantitative assessment. Iba-1-positive cells with polySia-positive dots of at least $5 \mu \mathrm{m}^{2}$ were counted in three bins at distances

Since calcium affects interactions of polySia with proteins, probably by stabilizing conformational epitopes of polySia [53], interactions of polySia with ST8SIA4 could mediate the calcium-dependent retention of polySia-NRP2 and poly-Sia-ESL-1 in the Golgi. Alterations of these between 0 and 50, 50 and 200, 200 and $400 \mu \mathrm{m}$ from the wound channel. A total of 134 polySia-positive cells were detected on sections of $n=5$ lesioned brains [one section per brain evaluated, mean per section $=27 \pm 8.4$ (s.e.m)]. Distributions are shown in $\%$ of polySiapositive cells (g) and in \% of all Iba-1-positive cells detected in the evaluated areas (h). Per bin, the individual values and means are plotted. Repeated measure one-way ANOVA indicated significant differences and results from Tukey's post hoc test are shown ${ }^{* *} p<0.01$, $* * * p<0.001, * * * * p<0.0001)$

interactions caused by decreasing calcium levels could, therefore, trigger their discharge. Alternatively, or in addition, other poly-Sia-binding factors could engage in calcium-dependent mechanisms that regulate cargo sorting and exit from the trans-Golgi compartment [54]. 
a

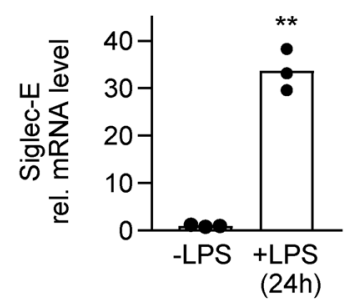

b

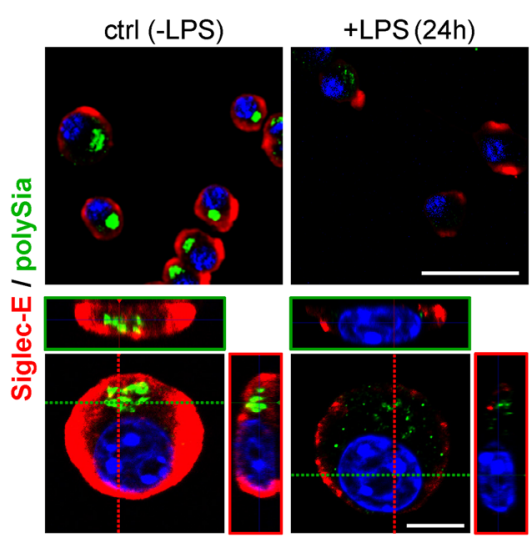

c

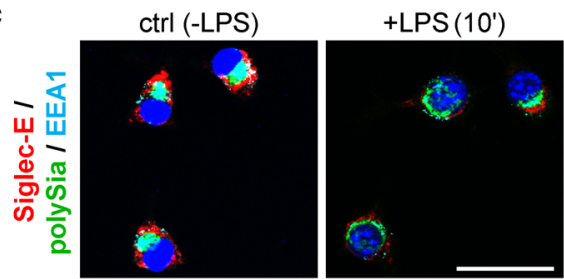

ctrl (-LPS)
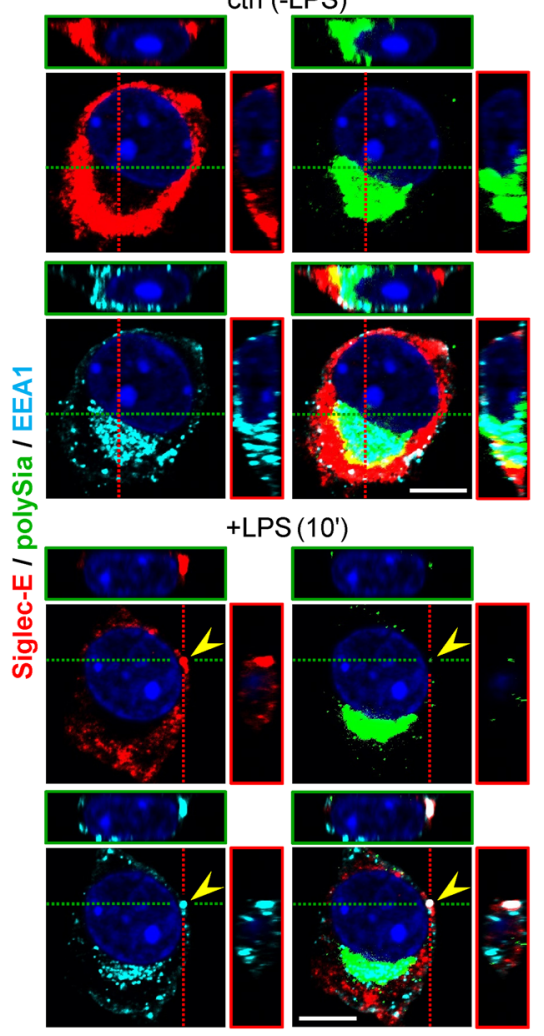

d

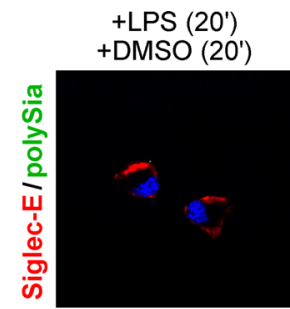

no LPS (20h)

e

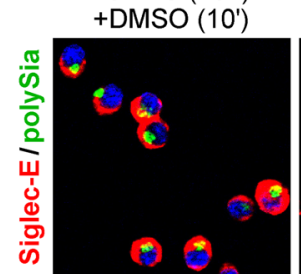

+LPS (20h)

f +genistein $\left(10^{\prime}\right)$

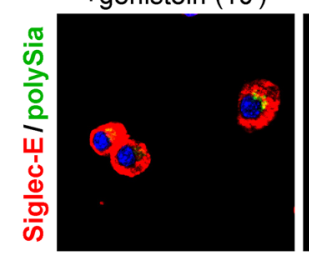

+LPS (20h)

g +medium change

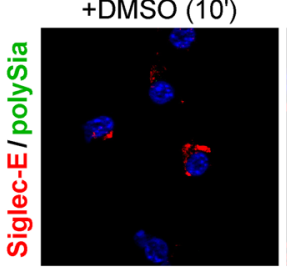

h

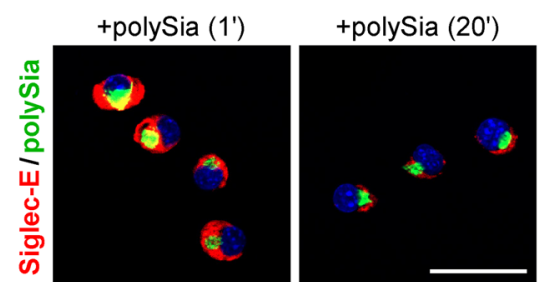

i

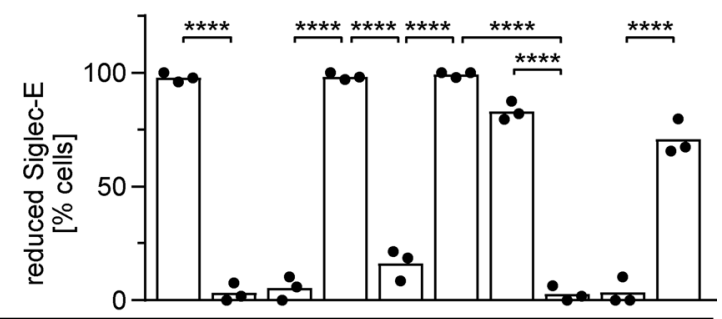

\begin{tabular}{|c|c|c|c|c|c|c|c|c|c|c|}
\hline LPS & $20^{\circ}$ & $20^{\prime}$ & - & $20 \mathrm{~h}$ & $20 \mathrm{~h}$ & $20 \mathrm{~h}$ & $20 \mathrm{~h}$ & $20 \mathrm{~h}$ & - & - \\
\hline DMSO & $20^{\prime}$ & $20^{\prime}$ & $10^{\prime}$ & $10^{\prime}$ & $10^{\prime}$ & $10^{\prime}$ & $10^{\prime}$ & $10^{\prime}$ & - & - \\
\hline Medium change & - & - & - & - & - & - & + & + & - & - \\
\hline Genistein & - & $20^{\prime}$ & - & - & $10^{\prime}$ & - & - & - & - & - \\
\hline TAK-242 & - & - & - & - & - & $10^{\prime}$ & - & $10^{\prime}$ & - & - \\
\hline polySia & - & - & - & - & - & - & - & - & $1^{\prime}$ & $20^{\prime}$ \\
\hline
\end{tabular}


४Fig. 5 LPS-induced changes of Siglec-E in BV2 microglia. a Analysis by quantitative real-time RT-PCR reveals a strong increase of Siglec-E mRNA in cells treated with $1-\mu \mathrm{g} / \mathrm{ml}$ LPS for $24 \mathrm{~h}$. Individual values and means from 3 independent treatments per group are plotted. ${ }^{*} p<0.01$, unpaired $t$ test. b Immunofluorescence detection of Siglec-E (red) and polySia (green). Nuclear counterstain with DAPI (blue). Staining patterns before (control, ctrl) and after treatment with $1-\mu \mathrm{g} / \mathrm{ml}$ LPS for $24 \mathrm{~h}$. Lower panels show 3D reconstructions at higher magnification. c Colocalization of Siglec-E (red) and polySia (green) with the endosomal marker EEA1 (cyan). Staining patterns before (control, ctrl) and after treatment with $1-\mu \mathrm{g} / \mathrm{ml}$ LPS for $10 \mathrm{~min}$. Lower panels show 3D reconstructions of single and merged channels with nuclear counterstain (DAPI, blue) at higher magnification. $\mathbf{d}-\mathbf{h}$ Detection of Siglec-E (red) and polySia (green) as in b. d Staining patterns after 20 min of LPS treatment in the presence of solvent $(1-\mu \mathrm{l} / \mathrm{ml}$ DMSO, left) or $200-\mu \mathrm{M}$ genistein (right). e, f Staining patterns after incubation for $20 \mathrm{~h}$ without or with LPS followed by $10 \mathrm{~min}$ with $1-\mu \mathrm{l} / \mathrm{ml} \mathrm{DMSO}(\mathbf{e}), 200-\mu \mathrm{M}$ genistein, or $1-\mu \mathrm{M}$ TAK-242 (f), as indicated. Genistein and TAK-242 were added as $1-\mu \mathrm{l} / \mathrm{ml}$ stock solution in DMSO. $\mathbf{g}$ Incubation of LPS-treated cells with DMSO and TAK-242 as in e and f, but this time the cell culture medium was changed to apply DMSO and TAK-242. h Staining patterns after incubation with polySia $(10 \mu \mathrm{g} / \mathrm{ml})$ for $1 \mathrm{~min}$ (left) or $20 \mathrm{~min}$ (right). The strong Siglec-E signals under control conditions without LPS (b, $\mathbf{c}, \mathbf{e}, \mathbf{h})$ and after genistein treatment $(\mathbf{d}, \mathbf{f})$ are overexposed to enable a visualization of the weak signals in LPS-treated cells with the same camera setting. Scale bars, $50 \mu \mathrm{m}$ in b and c (upper panels) and in $\mathbf{d}-\mathbf{h} ; 10 \mu \mathrm{m}$ in $\mathbf{b}$ and $\mathbf{c}$, lower panels. i Quantitative assessment of reduced Siglec-E cell surface staining under the conditions shown in $\mathbf{d}-\mathbf{h}$. Based on the densitometric evaluation of signal intensities of 108 cells treated for $10 \mathrm{~min}$ with DMSO in the absence of LPS, intensities below 50\% of the mean Siglec-E signal intensity under these conditions were considered "reduced". Per well, a minimum of 20 cells in 3 randomly selected frames with at least 5 cells each were evaluated and the percentage of cells with reduced Siglec-E immunoreactivity was calculated. Individual values and means of 3 wells per condition are plotted. One-way ANOVA indicated significant differences $(p<0.0001)$ and results from Tukey's post hoc test are shown for selected comparisons $(* * * * p<0.0001)$

In contrast to the complete loss of cell-associated polySia after $20 \mathrm{~min}$ of LPS induction, which is due to metalloproteinase-dependent ectodomain shedding of polySiaESL-1 and polySia-NRP2 [5], the accumulation of polySia at the cell surface of 4-C $m \mathrm{C}$-treated cells persisted for at least $20 \mathrm{~min}$. This indicates that the mere presentation of the polysialylated proteins at the cell surface as caused by the RyR-dependent manipulation of internal calcium levels is not sufficient for ectodomain shedding. Instead, the responsible sheddase must be recruited and/or activated by an alternative mechanism. Although it is well known that a number of key metalloproteinases are upregulated during LPS-induced microglia activation $[55,56]$, the rapid depletion of cell-associated polySia precludes a transcriptional regulation.

Only recently, first evidence became available that Siglec$\mathrm{E}$ is able to bind polySia and that knockdown of Siglec-E abolishes the response of cultured microglia to experimentally applied polySia $[9,17]$. In contrast to a glycan array study indicating a manifold stronger binding of Siglec-E to $\alpha 2,8$-linked di- and trisialic acid as compared to oligosialic acids with DPs between 4 and 11 [16], we now demonstrate that application of DP3 to murine microglia cannot mimic the physiological effect of polySia (colominic acid) with an average DP of about 50. Similarly, only polySia with an average DP of 20, but not oligosialic acid with DP6 was able to inhibit LPS-induced activation of human THP-1 macrophages [8], although studies with Siglec-11-Fc chimera indicated binding of short oligomers [15]. The reasons for these discrepancies between binding and physiological effects remain to be further explored. However, in analogy to the observation that multivalent display of DP2 on nanoparticles, but not soluble DP2, causes Siglec-E clustering and inhibits LPS-induced macrophage activation [57], it appears likely that only polySia but not soluble DP3 is able to induce Siglec-E oligomerization and thereby inhibitory signaling.

By the use of CRISPR/spCas9-mediated knockout, we corroborate that experimentally applied polySia is no longer able to inhibit LPS-induced activation of Siglec-E-deficient microglia. Importantly, we also show that Siglec-E-negative microglia exhibit a marked increase of activation in response to LPS. This is highly reminiscent of the augmented LPS induction of microglia obtained from ST8SIA4-deficient mice, i.e., microglia that are not able to produce and release polySia [4]. Thus, in the absence of any external source of polySia, the deletion of the putative polySia receptor has the same effect as the elimination of polySia biosynthesis, i.e., the cell-intrinsic source of the assumed ligand. Taken together, these findings imply that shedding of polysialylated proteins is part of a mechanism for negative feedback inhibition of LPS-induced microglia, in which the released protein-attached polySia activates Siglec-E as a ligand interacting in trans. Consistent with this model, LPS-induced ST8SIA4-negative microglia are still responsive to experimentally applied polySia indicating uncompromised sensing [4]. Conversely, the LPS-induced activation of SiglecE-deficient microglia can still be inhibited by minocycline, proving that the responsiveness to unrelated anti-inflammatory treatment is maintained (this study).

Regarding the spatiotemporal distribution of SiglecE immunoreactivity, the strong reduction of Siglec-E on LPS-induced microglia stands in stark contrast with the strong up-regulation of Siglec-E on the mRNA level. The strong reduction of Siglec-E also appears contradictory to the finding that Siglec-E is required for polySia-mediated inhibition. However, these data might be explained by endocytosis of Siglec-E upon ligand binding, which seems to be a general feature of Siglecs [11]. Indeed, intracellular Siglec-E staining and colocalization with the early endosomal marker EEA1 as well as with polySia could be detected during the early phase of LPS induction. Furthermore, inhibition with genistein for 10 or 20 min not only prevented the reduction, but also caused a progressive accumulation 
Fig. 6 Loss of Siglec-E abrogates responsiveness to polySia and enhances LPS-induced activation. a Compared to wildtype BV2 cells $\left(\right.$ Siglece $\left.^{+/+}\right)$, the immunoreactivity of Siglec-E (red), but not polySia (green) is abolished by CRISPR/spCas9-mediated knockout of Siglece Siglece $^{-1-}$, clone D19). Nuclear counterstain with DAPI (blue). Scale bar, $50 \mu \mathrm{m}$. b Comparable to the effect of preincubation with $60-\mu \mathrm{M}$ minocycline for $2 \mathrm{~h}$, application of polySia $(5 \mu \mathrm{g} /$ $\mathrm{ml}$ ) inhibits the LPS-induced NO production of Siglece ${ }^{+/+}$but not Siglece $^{-/-}$BV2 microglia (clone D19). In addition, the LPS-induced NO production of Siglece ${ }^{-1-}$ microglia was significantly higher. Where indicated (LPS +), 1- $\mu \mathrm{g} / \mathrm{ml}$ LPS was applied for $24 \mathrm{~h}$. c, d During $24 \mathrm{~h}$ of LPS treatment, Siglec-E-negative cells also showed a significantly more pronounced increase of TNF and IL-6 mRNA levels. In b-d, individual values and means from $n=3$ independent treatments per group are plotted. Mixed two-way ANOVA indicated significant differences and results from Holms-Sidak post hoc test are shown for selected group comparisons $(* p<0.05, * * p<0.01$, $* * * p<0.001, * * * * p<0.0001)$

of Siglec-E at the surface of LPS-treated BV2 microglia, even when applied after $20 \mathrm{~h}$ of LPS induction. This is comparable to the inhibitory effect of genistein on the clathrinindependent endocytosis of Siglec-F, another CD33-related murine Siglec, trafficking to lysosomes for degradation, when induced by anti-Siglec-F antibody ligation [40]. Selective inhibition of TLR4 signaling by TAK-242 reinstated the intracellular accumulation of polySia but in contrast to the effect of genistein, TAK-242 was only able to restore SiglecE on the surface of LPS-induced cells when applied together with a change of the cell culture medium. This indicates that the internalization of Siglec-E in LPS-induced microglia is regulated differently from the release of polysialylated protein and not caused by TLR4 signaling or cis-interactions with TLR4, as implicated by previous work on the role of Siglec-E in the endocytosis of activated TLR4 [58, 59]. Our data rather support the assumption that Siglec-E is internalized by receptor clustering and/or activation induced by interactions with shed polySia in trans. This is compatible with a recent report concluding that the inhibitory effects of Siglec-E on LPS-induced macrophages depend on activation by trans-interacting ligands [39].

An unexpected finding with high relevance for all future studies on possible physiological consequences of polysialylated protein shedding was that the release is not just a one-time discharge of polySia carriers assembled in the Golgi compartment of cultured microglia. Instead, production and release appear to continue for at least $24 \mathrm{~h}$ after LPS induction in vitro and a rough estimate of the released amounts indicated that they are sufficient to exert inhibitory effects. Correspondingly, the presence of polySia in a small proportion of microglia in some distance around a brain lesion and its absence from highly activated microglia in direct vicinity to the lesion site suggest that polysialylated proteins, after a transient accumulation in the Golgi, are continuously released by these cells in vivo, although it is not possible to directly detect this by immunohistochemistry. a

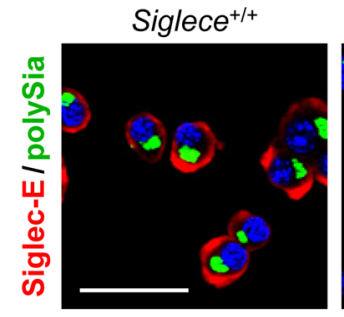
Siglece-1-
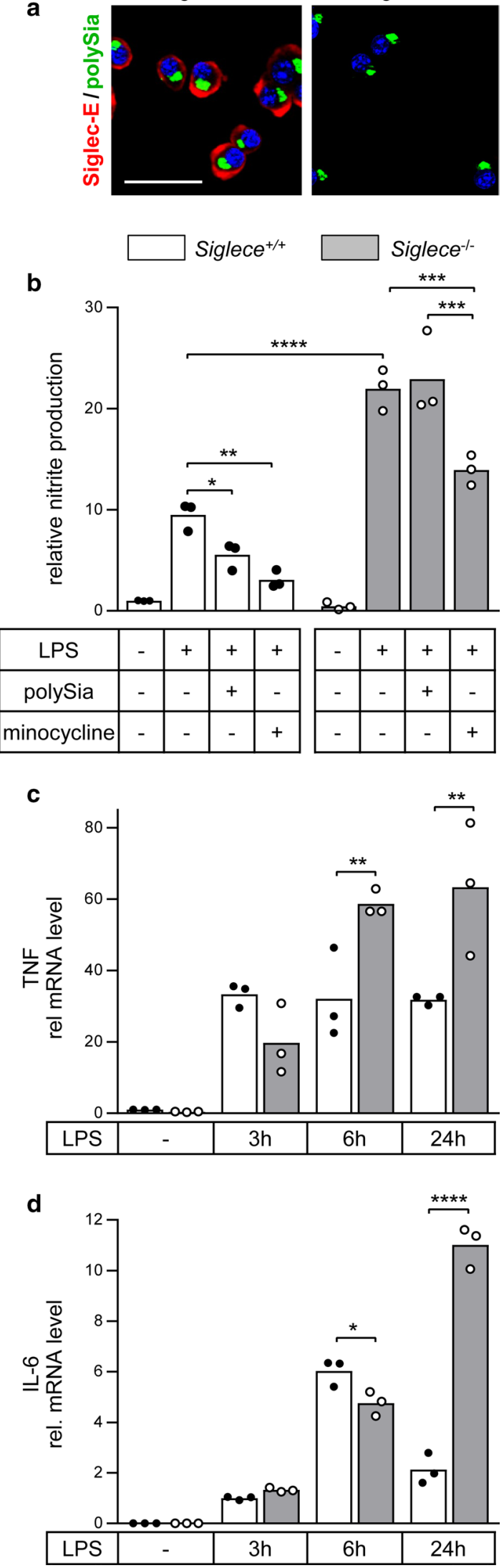
A major goal of future experiments, therefore, will be to develop appropriate sampling and analytical methods to detect soluble polySia-NRP2 and polySia-ESL-1 in freshly isolated brain tissue following TBI.

The termination of inflammatory activation by inhibitory, ITIM-containing receptors is an essential component of a proportionate and effective immune response [60]. In this regard, counteracting the inflammatory activation of microglia by shedding of polySia-presenting proteins may be beneficial for the outcome of TBI. Furthermore, externally applied polySia might be a therapeutic avenue to potentiate the anti-inflammatory effect in TBI, similar to current approaches to inhibit the activation of microglia and infiltrating macrophages, for instance, by application of minocycline, or by therapeutic modulation of TLR signaling [46, 61, 62]. Minocycline, however, not only reduces chronic microglial activation after brain trauma but also leads to increased neurodegeneration [63], indicating the need for a balanced approach to modulate neuroinflammation [64]. Notably, externally added polySia is as effective as minocycline in inhibiting inflammatory activation in primary and stem cell-derived $[4,5]$ as well as in BV2 microglia (this study). Future studies should, therefore, explore the role of polySia shedding in TBI as well as the effects of externally added polySia on injury-induced microglia.

Acknowledgements Open Access funding provided by Projekt DEAL. We thank Martina Mühlenhoff, Iris Röckle, Jan H. Hütte and Sebastian Werneburg for helpful comments and technical advice, Gerd Bicker for wildtype BV2 cells, Wolfgang Löscher and Christopher Käufer for providing murine brain sections, Martin Wild for ESL-1-specific antibody, Paul Crocker for Siglec-E-specific antibody, and Dirk Heckl for plasmid DHC\#4731.

Author contributions $\mathrm{HT}$ and $\mathrm{HH}$ designed the project and the experiments, HT and JB performed the experiments, HT and HH analyzed the experiments, HT and $\mathrm{HH}$ wrote the manuscript.

Funding This work was funded by the Deutsche Forschungsgemeinschaft (DFG, German Research Foundation), project numbers 324633948 and 432236295 (DFG grants Hi 678/9-1 and Hi 678/10-1 to H.H.).

\section{Compliance with ethical standards}

Conflict of interest The authors declare that they have no conflict of interest.

Ethical approval The experiments comply with the current laws of the country in which they were performed.

Open Access This article is licensed under a Creative Commons Attribution 4.0 International License, which permits use, sharing, adaptation, distribution and reproduction in any medium or format, as long as you give appropriate credit to the original author(s) and the source, provide a link to the Creative Commons licence, and indicate if changes were made. The images or other third party material in this article are included in the article's Creative Commons licence, unless indicated otherwise in a credit line to the material. If material is not included in the article's Creative Commons licence and your intended use is not permitted by statutory regulation or exceeds the permitted use, you will need to obtain permission directly from the copyright holder. To view a copy of this licence, visit http://creativecommons.org/licenses/by/4.0/.

\section{References}

1. Varki A, Schnaar RL, Schauer R (2017) Sialic acids and other nonulosonic acids. In: Varki A, Cummings RD, Esko JD, et al. (eds) Essentials of gycobiology, 3rd edn. Cold Spring Harbor Laboratory Press, Cold Spring Harbor (NY), pp 179-195. https ://doi.org/10.1101/glycobiology.3e.015

2. Schnaar RL, Gerardy-Schahn R, Hildebrandt H (2014) Sialic acids in the brain: gangliosides and polysialic acid in nervous system development, stability, disease, and regeneration. Physiol Rev 94(2):461-518. https://doi.org/10.1152/physrev.00033.2013

3. Rutishauser U (2008) Polysialic acid in the plasticity of the developing and adult vertebrate nervous system. Nat Rev Neurosci 9(1):26-35. https://doi.org/10.1038/nrn2285

4. Werneburg S, Mühlenhoff M, Stangel M, Hildebrandt H (2015) Polysialic acid on SynCAM 1 in NG2 cells and on neuropilin-2 in microglia is confined to intracellular pools that are rapidly depleted upon stimulation. Glia 63(7):1240-1255. https://doi. org/10.1002/glia.22815

5. Werneburg S, Buettner FF, Erben L, Mathews M, Neumann H, Mühlenhoff M, Hildebrandt H (2016) Polysialylation and lipopolysaccharide-induced shedding of E-selectin ligand-1 and neuropilin- 2 by microglia and THP-1 macrophages. Glia 64(8):1314-1330. https://doi.org/10.1002/glia.23004

6. Hildebrandt H, Mühlenhoff M, Gerardy-Schahn R (2010) Polysialylation of NCAM. Adv Exp Med Biol 663:95-109. https:// doi.org/10.1007/978-1-4419-1170-4 6

7. Kallolimath S, Castilho A, Strasser R, Grunwald-Gruber C, Altmann F, Strubl S, Galuska CE, Zlatina K, Galuska SP, Werner S, Thiesler H, Werneburg S, Hildebrandt H, Gerardy-Schahn R, Steinkellner H (2016) Engineering of complex protein sialylation in plants. Proc Natl Acad Sci USA 113(34):9498-9503. https://doi.org/10.1073/pnas.1604371113

8. Shahraz A, Kopatz J, Mathy R, Kappler J, Winter D, Kapoor S, Schutza V, Scheper T, Gieselmann V, Neumann H (2015) Anti-inflammatory activity of low molecular weight polysialic acid on human macrophages. Sci Rep 5:16800. https://doi. org/10.1038/srep 16800

9. Karlstetter M, Kopatz J, Aslanidis A, Shahraz A, Caramoy A, Linnartz-Gerlach B, Lin Y, Luckoff A, Fauser S, Duker K, Claude J, Wang Y, Ackermann J, Schmidt T, Hornung V, Skerka C, Langmann T, Neumann H (2017) Polysialic acid blocks mononuclear phagocyte reactivity, inhibits complement activation, and protects from vascular damage in the retina. EMBO Mol Med 9(2):154-166. https://doi.org/10.15252/emmm.201606627

10. Varki A, Schnaar RL, Crocker PR (2017) I-type lectins. In: Varki A, Cummings RD, Esko JD, et al. (eds) Essentials of glycobiology, 3rd edn. Cold Spring Harbor Laboratory Press, Cold Spring Harbor (NY), pp 453-467. https://doi.org/10.1101/ glycobiology.3e.035

11. Macauley MS, Crocker PR, Paulson JC (2014) Siglec-mediated regulation of immune cell function in disease. Nat Rev Immunol 14(10):653-666. https://doi.org/10.1038/nri3737

12. Crocker PR, Paulson JC, Varki A (2007) Siglecs and their roles in the immune system. Nat Rev Immunol 7(4):255-266. https ://doi.org/10.1038/nri2056 
13. Linnartz-Gerlach B, Kopatz J, Neumann H (2014) Siglec functions of microglia. Glycobiology 24(9):794-799. https://doi. org/10.1093/glycob/cwu044

14. Wang Y, Neumann H (2010) Alleviation of neurotoxicity by microglial human Siglec-11. J Neurosci 30(9):3482-3488. https ://doi.org/10.1523/JNEUROSCI.3940-09.2010

15. Angata T, Kerr SC, Greaves DR, Varki NM, Crocker PR, Varki A (2002) Cloning and characterization of human Siglec-11-a recently evolved signaling molecule that can interact with SHP-1 and SHP-2 and is expressed by tissue macrophages, including brain microglia. J Biol Chem 277(27):24466-24474. https://doi.org/10.1074/jbc.M202833200

16. Redelinghuys P, Antonopoulos A, Liu Y, Campanero-Rhodes MA, McKenzie E, Haslam SM, Dell A, Feizi T, Crocker PR (2011) Early murine T-lymphocyte activation is accompanied by a switch from $\mathrm{N}$-Glycolyl- to $\mathrm{N}$-acetyl-neuraminic acid and generation of ligands for siglec-E. J Biol Chem 286(40):3452234532. https://doi.org/10.1074/jbc.M111.243410

17. Schwarz F, Landig CS, Siddiqui S, Secundino I, Olson J, Varki N, Nizet V, Varki A (2017) Paired Siglec receptors generate opposite inflammatory responses to a human-specific pathogen. EMBO J 36(6):751-760. https://doi.org/10.15252/embj.20169 5581

18. Sakuma T, Nishikawa A, Kume S, Chayama K, Yamamoto T (2014) Multiplex genome engineering in human cells using allin-one CRISPR/Cas9 vector system. Sci Rep 4:5400. https://doi. org/10.1038/srep05400

19. Heckl D, Kowalczyk MS, Yudovich D, Belizaire R, Puram RV, McConkey ME, Thielke A, Aster JC, Regev A, Ebert BL (2014) Generation of mouse models of myeloid malignancy with combinatorial genetic lesions using CRISPR-Cas9 genome editing. Nat Biotechnol 32(9):941-946. https://doi.org/10.1038/nbt.2951

20. Stummeyer K, Dickmanns A, Mühlenhoff M, Gerardy-Schahn R, Ficner R (2005) Crystal structure of the polysialic aciddegrading endosialidase of bacteriophage K1F. Nat Struct Mol Biol 12(1):90-96. https://doi.org/10.1038/nsmb874

21. Frosch M, Gorgen I, Boulnois GJ, Timmis KN, Bitter-Suermann D (1985) NZB mouse system for production of monoclonal antibodies to weak bacterial antigens: isolation of an $\mathrm{IgG}$ antibody to the polysaccharide capsules of Escherichia coli K1 and group B meningococci. Proc Natl Acad Sci USA 82(4):1194-1198. https://doi.org/10.1073/pnas.82.4.1194

22. Harlow E, Lane D (2006) Antibody purification on protein A or protein G columns. CSH Protoc. https://doi.org/10.1101/pdb. prot 4283

23. Tantra M, Kröcher T, Papiol S, Winkler D, Röckle I, Jatho J, Burkhardt H, Ronnenberg A, Gerardy-Schahn R, Ehrenreich H, Hildebrandt H (2014) St8sia2 deficiency plus juvenile cannabis exposure in mice synergistically affect higher cognition in adulthood. Behav Brain Res 275:166-175. https://doi.org/10.1016/j. bbr.2014.08.062

24. Schidlitzki A, Twele F, Klee R, Waltl I, Römermann K, Broer S, Meller S, Gerhauser I, Rankovic V, Li D, Brandt C, Bankstahl M, Töllner K, Löscher W (2017) A combination of NMDA and AMPA receptor antagonists retards granule cell dispersion and epileptogenesis in a model of acquired epilepsy. Sci Rep 7(1):12191. https://doi.org/10.1038/s41598-017-12368-6

25. Twele F, Tollner K, Brandt C, Löscher W (2016) Significant effects of sex, strain, and anesthesia in the intrahippocampal kainate mouse model of mesial temporal lobe epilepsy. Epilepsy Behav 55:47-56. https://doi.org/10.1016/j.yebeh.2015.11.027

26. Ran FA, Hsu PD, Wright J, Agarwala V, Scott DA, Zhang F (2013) Genome engineering using the CRISPR-Cas9 system. Nat Protoc 8(11):2281-2308. https://doi.org/10.1038/nprot .2013 .143
27. Konze SA, van Diepen L, Schroder A, Olmer R, Moller H, Pich A, Weissmann R, Kuss AW, Zweigerdt R, Buettner FF (2014) Cleavage of E-cadherin and beta-catenin by calpain affects Wnt signaling and spheroid formation in suspension cultures of human pluripotent stem cells. Mol Cell Proteomics 13(4):990-1007. https ://doi.org/10.1074/mcp.M113.033423

28. Schiff M, Weinhold B, Grothe C, Hildebrandt H (2009) NCAM and polysialyltransferase profiles match dopaminergic marker gene expression but polysialic acid is dispensable for development of the midbrain dopamine system. J Neurochem 110(5):16611673. https://doi.org/10.1111/j.1471-4159.2009.06267.x

29. Aslanidis A, Karlstetter M, Scholz R, Fauser S, Neumann H, Fried C, Pietsch M, Langmann T (2015) Activated microglia/ macrophage whey acidic protein (AMWAP) inhibits NFkappaB signaling and induces a neuroprotective phenotype in microglia. J Neuroinflammation 12:77. https://doi.org/10.1186/s1297 4-015-0296-6

30. Yee CS, Yao Y, Xu Q, McCarthy B, Sun-Lin D, Tone M, Waldmann $\mathrm{H}$, Chang $\mathrm{CH}$ (2005) Enhanced production of IL-10 by dendritic cells deficient in CIITA. J Immunol 174(3):1222-1229. https://doi.org/10.4049/jimmunol.174.3.1222

31. Untergasser A, Cutcutache I, Koressaar T, Ye J, Faircloth BC, Remm M, Rozen SG (2012) Primer3-new capabilities and interfaces. Nucleic Acids Res 40(15):e115. https://doi.org/10.1093/nar/ gks596

32. Ye J, Coulouris G, Zaretskaya I, Cutcutache I, Rozen S, Madden TL (2012) Primer-BLAST: a tool to design target-specific primers for polymerase chain reaction. BMC Bioinform 13:134. https:// doi.org/10.1186/1471-2105-13-134

33. Stansley B, Post J, Hensley K (2012) A comparative review of cell culture systems for the study of microglial biology in Alzheimer's disease. J Neuroinflammation 9:115. https://doi. org/10.1186/1742-2094-9-115

34. Hoffmann A, Kann O, Ohlemeyer C, Hanisch UK, Kettenmann $\mathrm{H}$ (2003) Elevation of basal intracellular calcium as a central element in the activation of brain macrophages (microglia): suppression of receptor-evoked calcium signaling and control of release function. J Neurosci 23(11):4410-4419. https://doi.org/10.1523/ JNEUROSCI.23-11-04410.2003

35. Klegeris A, Choi HB, McLarnon JG, McGeer PL (2007) Functional ryanodine receptors are expressed by human microglia and THP-1 cells: their possible involvement in modulation of neurotoxicity. J Neurosci Res 85(10):2207-2215. https://doi. org/10.1002/jnr.21361

36. Stence N, Waite M, Dailey ME (2001) Dynamics of microglial activation: a confocal time-lapse analysis in hippocampal slices. Glia 33(3):256-266. https://doi.org/10.1002/1098-1136(20010 3)33:3<256::AID-GLIA1024>3.0.CO;2-J

37. Beynon SB, Walker FR (2012) Microglial activation in the injured and healthy brain: what are we really talking about? Practical and theoretical issues associated with the measurement of changes in microglial morphology. Neuroscience 225:162-171. https://doi. org/10.1016/j.neuroscience.2012.07.029

38. Boyd CR, Orr SJ, Spence S, Burrows JF, Elliott J, Carroll HP, Brennan K, Gabhann JN, Coulter WA, Johnston JA, Jefferies CA (2009) Siglec-E is up-regulated and phosphorylated following lipopolysaccharide stimulation in order to limit TLR-driven cytokine production. J Immunol 183(12):7703-7709. https://doi. org/10.4049/jimmunol.0902780

39. Nagala M, McKenzie E, Richards H, Sharma R, Thomson S, Mastroeni P, Crocker PR (2017) Expression of Siglec-E alters the proteome of lipopolysaccharide (LPS)-activated macrophages but does not affect LPS-driven cytokine production or Toll-like receptor 4 endocytosis. Front Immunol 8:1926. https://doi.org/10.3389/ fimmu.2017.01926 
40. Tateno H, Li H, Schur MJ, Bovin N, Crocker PR, Wakarchuk WW, Paulson JC (2007) Distinct endocytic mechanisms of CD22 (Siglec-2) and Siglec-F reflect roles in cell signaling and innate immunity. Mol Cell Biol 27(16):5699-5710. https://doi. org/10.1128/mcb.00383-07

41. Mayor S, Parton RG, Donaldson JG (2014) Clathrin-independent pathways of endocytosis. Cold Spring Harb Perspect Biol 6:a016758. https://doi.org/10.1101/cshperspect.a016758

42. Pelkmans L, Puntener D, Helenius A (2002) Local actin polymerization and dynamin recruitment in SV40-induced internalization of caveolae. Science 296(5567):535-539. https://doi.org/10.1126/ science. 1069784

43. Jeong JW, Lee HH, Han MH, Kim GY, Kim WJ, Choi YH (2014) Anti-inflammatory effects of genistein via suppression of the tolllike receptor 4-mediated signaling pathway in lipopolysaccharidestimulated BV2 microglia. Chem Biol Interact 212:30-39. https:// doi.org/10.1016/j.cbi.2014.01.012

44. Matsunaga N, Tsuchimori N, Matsumoto T, Ii M (2011) TAK242 (resatorvid), a small-molecule inhibitor of Toll-like receptor (TLR) 4 signaling, binds selectively to TLR4 and interferes with interactions between TLR4 and its adaptor molecules. Mol Pharmacol 79(1):34-41. https://doi.org/10.1124/mol.110.068064

45. Kobayashi K, Imagama S, Ohgomori T, Hirano K, Uchimura K, Sakamoto K, Hirakawa A, Takeuchi H, Suzumura A, Ishiguro N, Kadomatsu K (2013) Minocycline selectively inhibits M1 polarization of microglia. Cell Death Dis 4:e525. https://doi. org/10.1038/cddis.2013.54

46. Gyoneva S, Ransohoff RM (2015) Inflammatory reaction after traumatic brain injury: therapeutic potential of targeting cell-cell communication by chemokines. Trends Pharmacol Sci 36(7):471480. https://doi.org/10.1016/j.tips.2015.04.003

47. Kumar A, Alvarez-Croda DM, Stoica BA, Faden AI, Loane DJ (2016) Microglial/macrophage polarization dynamics following traumatic brain injury. J Neurotrauma 33(19):1732-1750. https:// doi.org/10.1089/neu.2015.4268

48. Franco L, Bodrato N, Moreschi I, Usai C, Bruzzone S, Scarfi S, Zocchi E, De Flora A (2006) Cyclic ADP-ribose is a second messenger in the lipopolysaccharide-stimulated activation of murine N9 microglial cell line. J Neurochem 99(1):165-176. https://doi. org/10.1111/j.1471-4159.2006.04031.x

49. Lissandron V, Podini P, Pizzo P, Pozzan T (2010) Unique characteristics of $\mathrm{Ca} 2+$ homeostasis of the trans-Golgi compartment. Proc Natl Acad Sci USA 107(20):9198-9203. https://doi. org/10.1073/pnas.1004702107

50. Pizzo P, Lissandron V, Capitanio P, Pozzan T (2011) Ca(2+) signalling in the Golgi apparatus. Cell Calcium 50(2):184-192. https ://doi.org/10.1016/j.ceca.2011.01.006

51. Mühlenhoff M, Rollenhagen M, Werneburg S, Gerardy-Schahn R, Hildebrandt H (2013) Polysialic acid: versatile modification of NCAM, SynCAM 1 and neuropilin-2. Neurochem Res 38(6):1134-1143. https://doi.org/10.1007/s11064-013-0979-2

52. Bhide GP, Fernandes NR, Colley KJ (2016) Sequence requirements for neuropilin-2 recognition by ST8SiaIV and polysialylation of its O-glycans. J Biol Chem 291(18):9444-9457. https:// doi.org/10.1074/jbc.M116.714329

53. Häyrinen J, Haseley S, Talaga P, Mühlenhoff M, Finne J, Vliegenthart JF (2002) High affinity binding of long-chain polysialic acid to antibody, and modulation by divalent cations and polyamines. Mol Immunol 39(7-8):399-411. https://doi.org/10.1016/S0161 $-5890(02) 00202-\mathrm{X}$
54. Pakdel M, von Blume J (2018) Exploring new routes for secretory protein export from the trans-Golgi network. Mol Biol Cell 29(3):235-240. https://doi.org/10.1091/mbc.E17-02-0117

55. Nuttall RK, Silva C, Hader W, Bar-Or A, Patel KD, Edwards DR, Yong VW (2007) Metalloproteinases are enriched in microglia compared with leukocytes and they regulate cytokine levels in activated microglia. Glia 55(5):516-526. https://doi.org/10.1002/ glia.20478

56. Lively S, Schlichter LC (2013) The microglial activation state regulates migration and roles of matrix-dissolving enzymes for invasion. J Neuroinflammation 10:75. https://doi. org/10.1186/1742-2094-10-75

57. Spence S, Greene MK, Fay F, Hams E, Saunders SP, Hamid U, Fitzgerald M, Beck J, Bains BK, Smyth P, Themistou E, Small DM, Schmid D, O'Kane CM, Fitzgerald DC, Abdelghany SM, Johnston JA, Fallon PG, Burrows JF, McAuley DF, Kissenpfennig A, Scott CJ (2015) Targeting Siglecs with a sialic aciddecorated nanoparticle abrogates inflammation. Sci Transl Med 7(303):303ra140. https://doi.org/10.1126/scitranslmed.aab3459

58. Wu Y, Ren D, Chen GY (2016) Siglec-E negatively regulates the activation of TLR 4 by controlling its endocytosis. J Immunol 197(8):3336-3347. https://doi.org/10.4049/jimmunol.1600772

59. Chen GY, Brown NK, Wu W, Khedri Z, Yu H, Chen X, Van de Vlekkert D, d'Azzo A, Zheng P, Liu Y (2014) Broad and direct interaction between TLR and Siglec families of pattern recognition receptors and its regulation by Neu1. Elife 3:e04066. https:// doi.org/10.7554/eLife.04066

60. Kane BA, Bryant KJ, McNeil HP, Tedla NT (2014) Termination of immune activation: an essential component of healthy host immune responses. J Innate Immun 6(6):727-738. https://doi. org/10.1159/000363449

61. Mao SS, Hua R, Zhao XP, Qin X, Sun ZQ, Zhang Y, Wu YQ, Jia MX, Cao JL, Zhang YM (2012) Exogenous administration of PACAP alleviates traumatic brain injury in rats through a mechanism involving the TLR4/MyD88/NF-kappaB pathway. J Neurotrauma 29(10):1941-1959. https://doi.org/10.1089/neu.2011.2244

62. Homsi S, Piaggio T, Croci N, Noble F, Plotkine M, MarchandLeroux C, Jafarian-Tehrani M (2010) Blockade of acute microglial activation by minocycline promotes neuroprotection and reduces locomotor hyperactivity after closed head injury in mice: a twelveweek follow-up study. J Neurotrauma 27(5):911-921. https://doi. org/10.1089/neu.2009.1223

63. Scott G, Zetterberg H, Jolly A, Cole JH, De Simoni S, Jenkins PO, Feeney C, Owen DR, Lingford-Hughes A, Howes O, Patel MC, Goldstone AP, Gunn RN, Blennow K, Matthews PM, Sharp DJ (2018) Minocycline reduces chronic microglial activation after brain trauma but increases neurodegeneration. Brain 141(2):459 471. https://doi.org/10.1093/brain/awx339

64. Russo MV, McGavern DB (2016) Inflammatory neuroprotection following traumatic brain injury. Science 353(6301):783-785. https://doi.org/10.1126/science.aaf6260

Publisher's Note Springer Nature remains neutral with regard to jurisdictional claims in published maps and institutional affiliations. 